\title{
Annual and Interannual Variability in the California Current System: Comparison of an Ocean State Estimate with a Network of Underwater Gliders
}

\author{
Katherine D. Zaba, Daniel L. Rudnick, Bruce D. Cornuelle, Ganesh Gopalakrishnan, \\ AND MATTHEW R. MAZLOFF \\ Scripps Institution of Oceanography, La Jolla, California
}

(Manuscript received 2 March 2018, in final form 4 October 2018)

\begin{abstract}
A data-constrained state estimate of the southern California Current System (CCS) is presented and compared with withheld California Cooperative Oceanic Fisheries Investigations (CalCOFI) data and assimilated glider data over 2007-17. The objective of this comparison is to assess the ability of the California State Estimate (CASE) to reproduce the key physical features of the CCS mean state, annual cycles, and interannual variability along the three sections of the California Underwater Glider Network (CUGN). The assessment focuses on several oceanic metrics deemed most important for characterizing physical variability in the CCS: $50-\mathrm{m}$ potential temperature, $80-\mathrm{m}$ salinity, and $26 \mathrm{~kg} \mathrm{~m}^{-3}$ isopycnal depth and salinity. In the time mean, the CASE reproduces large-scale thermohaline and circulation structures, including observed temperature gradients, shoaling isopycnals, and the locations and magnitudes of the equatorward California Current and poleward California Undercurrent. With respect to the annual cycle, the CASE captures the phase and, to a lesser extent, the magnitude of upper-ocean warming and stratification from late summer to early fall and of isopycnal heave during springtime upwelling. The CASE also realistically captures nearsurface diapycnal mixing during upwelling season and the semiannual cycle of the California Undercurrent. In terms of interannual variability, the most pronounced signals are the persistent warming and downwelling anomalies of 2014-16 and a positive isopycnal salinity anomaly that peaked with the 2015-16 El Niño.
\end{abstract}

\section{Introduction}

Given the economic and ecological relevance of the California Current System (CCS), there is great interest in characterizing its physical variability. This can be accomplished through dense observations, realistic models, or the complementary use of both. With the latter method, observations move the simulated ocean closer to reality through data assimilation and models can provide a full four-dimensional, dynamically consistent estimate of the ocean state. Our overarching scientific objective is to diagnose upper-ocean physical variability of the CCS by calculating time-varying mass, heat, and salt budgets. Data from the California Underwater Glider Network (CUGN; Fig. 1) along three across-shore lines (Rudnick et al. 2017) allow the calculation of some of the budget terms, but their limited alongshore resolution prevents the analysis of complete and closed budgets. To extend our analysis into the alongshore dimension, we use the California State Estimate (CASE), which assimilates CUGN temperature

\footnotetext{
Corresponding author: Katherine Zaba,kzaba@ucsd.edu
}

and salinity data along with other available in situ and remote ocean observations. The purpose of this paper is to assess CASE relative to observations. A second paper to follow will quantify physical budgets from CASE. Here, we compare the CASE solutions with withheld California Cooperative Oceanic Fisheries Investigations (CalCOFI) temperature and salinity data and with the CUGN to assess the realism of the state estimate especially with regard to annual and interannual variability that is well resolved in the CUGN observations.

Underwater gliders are well suited for sustained observations of boundary currents and their low-frequency variability. In the CCS, the CUGN was established in 2006 and has since collected the world's longest continuous glider time series, to our knowledge. Spray gliders measure subsurface pressure, temperature, salinity, velocity, and biological variables along CalCOFI lines 66.7, 80, and 90 (Fig. 1). To provide convenient access and enable scientific analyses, a regional climatology was constructed from the CUGN data (Rudnick et al. 2017). The CUGN climatology has several gridded products along each line: a mean field, an annual cycle, 

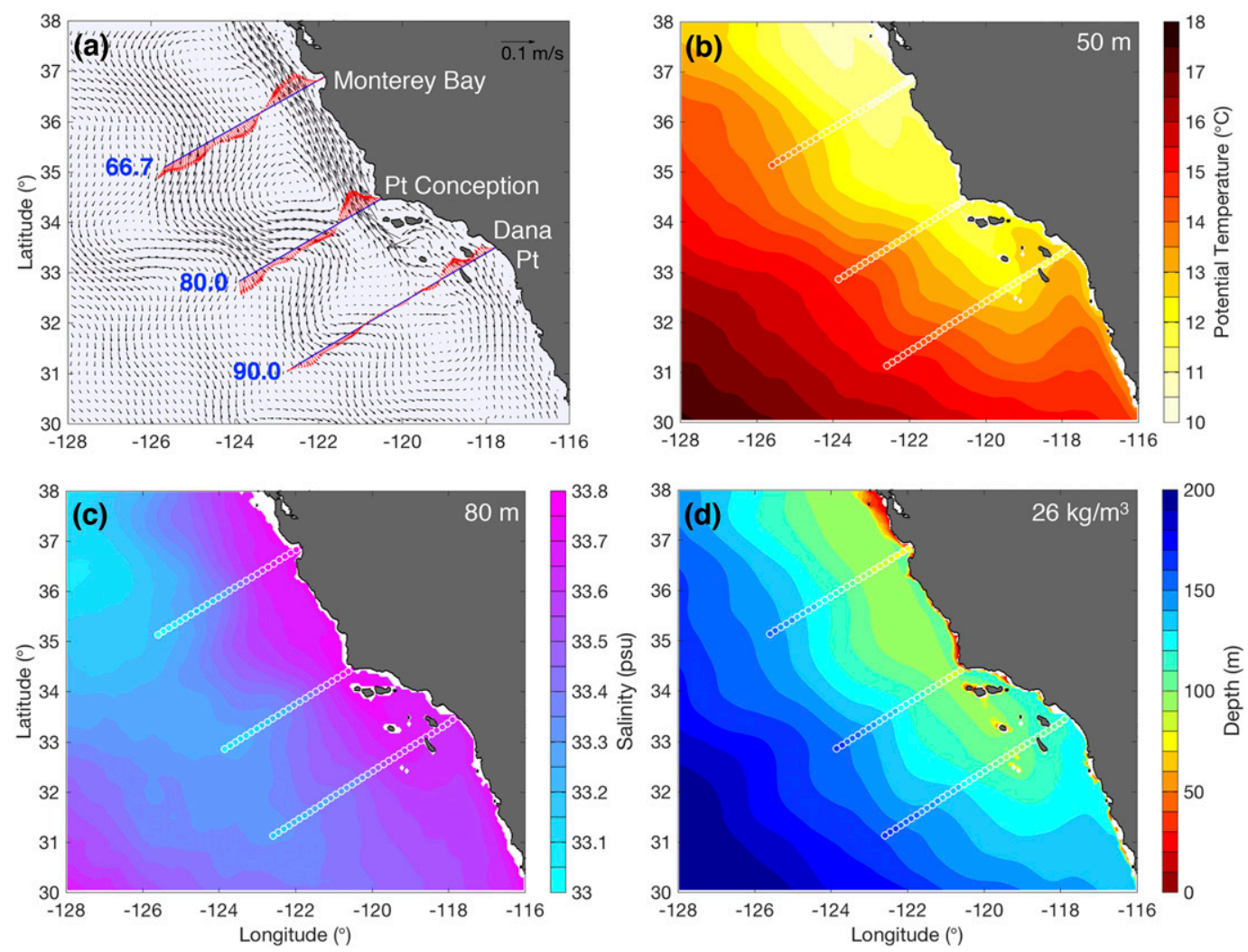

FIG. 1. Plan view of 2007-13 time-mean (a) depth-averaged velocity (0-500 m), (b) 50-m potential temperature, (c) $80-\mathrm{m}$ salinity, and (d) $26.0 \mathrm{~kg} \mathrm{~m}^{-3}$ isopycnal depth. The black arrows in (a) and color-filled contours in (b)-(d) represent mean model values from CASE; the red arrows in (a) and color-filled circles in (b)-(d) represent mean glider-measured values from the CUGN climatology along CalCOFI lines 66.7, 80, and 90, which are drawn in blue lines and labeled in (a). For visual clarity, the model velocities in (a) are binned to $(3 / 16)^{\circ}$ resolution, and the glider-measured data in (b)-(d) are subsampled at $15-\mathrm{km}$ along-section resolution. The area shown is a cropped portion of the full model domain, which extends from $130^{\circ}$ to $114^{\circ} \mathrm{W}$ and from $27.2^{\circ}$ to $40^{\circ} \mathrm{N}$.

and the anomaly from the annual cycle. Rudnick et al. (2017) discussed the annual cycle and the recent anomalous warming since 2014. The most robust results are revisited here to compare with CASE. Previous publications have used CUGN data to characterize the interannual anomalies caused by the 2009-10 El Niño (Todd et al. 2011a), the 2014-15 marine heat wave (Zaba and Rudnick 2016), and the 2015-16 El Niño (Jacox et al. 2016).

The numerical state estimate presented here, CASE, is the output of a regional, data-assimilating version of the Massachusetts Institute of Technology general circulation model (MITgcm) (Marshall et al. 1997a,b). By constraining the model to observations and by adjusting the model controls, data assimilation provides an optimized ocean state that is consistent with both the model dynamics and the observations. Edwards et al. (2015) describe data assimilation as a dynamical approach to interpolating and extrapolating sparse and intermittent oceanic data. The resulting four-dimensional ocean state estimate resolves broadly in space and time and is useful for placing observed physical features and variability within the context of a finely resolved spatiotemporal grid.

This version of CASE uses assimilation windows of 3-month duration to produce the state estimate. The assimilation setup is inherited from an earlier long-term version (4-yr assimilation window) of CASE, which was described and analyzed in several previous studies. Evaluations of long-term CASE showed that, relative to glider observations, it reproduced the structure and variability of the poleward velocity field but underestimated velocity magnitudes (Todd et al. 2011b), and it resolved upper-ocean thermohaline structures at spatial scales greater than $30 \mathrm{~km}$ (Todd et al. 2012). Mazloff et al. (2014) used the dynamic ocean topography field from long-term CASE to develop a regional geoid correction method. Furthermore, the corresponding adjoint model of CASE was used to perform passive tracer calculations that revealed the origins of 
CCS water parcels (Todd et al. 2012) and to perform sensitivity analyses of the forcing mechanisms that cause high-frequency coastal sea surface height ( $\mathrm{SSH}$ ) variability (Verdy et al. 2014). The latter (Verdy et al. 2014) showed that the linear assumption holds true over 100-day time scales. In other words, the adjoint-modelderived gradients that are needed for optimization have skill over the assimilation windows implemented in the current version of short-term CASE, which consists of 41 sequential, nonoverlapping 3-month estimates over 1 January 2007-31 March 2017.

A number of modeling groups have developed regional ocean data assimilation systems for the CCS, as discussed in Edwards et al. (2015). Most of them use the Regional Ocean Modeling System (ROMS; Edwards et al. 2015), which has a variety of assimilation methods enabled. Several recent forward (Kurapov et al. 2017) and dataassimilative models (Chao et al. 2017a; Neveu et al. 2016) have been implemented. The assimilation windows range from 1 day for sequential methods (Chao et al. 2017a) to 8 days for four-dimensional variational (4D-Var) methods (Neveu et al. 2016). In short-term CASE, the $4 \mathrm{D}$-Var is carried out in 3-month windows, which are much longer than those of other regional data assimilation systems (order of several days) but much shorter than that of former long-term CASE (order of several years). This choice of assimilation window was made to increase model controllability while still enforcing governing physics and capturing the continuous evolution of large-scale dynamics over weeks to months. Relative to the other regional data assimilation systems, CASE provides closed budgets over longer time periods but misses or smooths out shorter space and time-scale variability. Relative to former long-term CASE, the short-term solutions are closer to the constraints with better resolution of eddy variability, but this comes at the expense of minor discontinuities in the physical budgets at the transition of the 3-month windows. CASE is well suited for analyzing long-term means, seasonal cycles, and interannual variability, all of which will be assessed in this paper.

The primary objective of this study is to compare CASE with observations both assimilated and withheld. First, we compare CASE optimized and control solutions with SSH analyses. Second, we cross-validate the state estimate against withheld observations for an independent assessment of the model's overall accuracy at times and locations that are not necessarily constrained. Third, we process the state estimate in the same way as the glider data to produce a state estimate analog of the CUGN climatology, and we compare the two products to determine whether the CASE reproduces key physical features of the CCS mean state, annual cycles, and interannual variability along the glider lines. In doing so, we highlight metrics deemed most important for representing the fundamental aspects of CCS physical variability, for example, temperature at 50-m depth $T_{50 \mathrm{~m}}$, salinity at 80 -m depth $S_{80 \mathrm{~m}}$, and $26.0 \mathrm{~kg} \mathrm{~m}^{-3}$ isopycnal depth $z_{26 \mathrm{~kg} / \mathrm{m} 3}$ and salinity $S_{26 \mathrm{~kg} / \mathrm{m} 3}$. The $T_{50 \mathrm{~m}}, S_{80 \mathrm{~m}}$, and $z_{26 \mathrm{~kg} / \mathrm{m} 3}$ metrics are affected by upwelling/downwelling, which we define here to denote the vertical displacement of isotherms, isohalines, and isopycnals. By removing the effects of isoline heave, the $S_{26 \mathrm{~kg} / \mathrm{m} 3}$ metric represents horizontal advection anomalies. The remainder of this paper is organized as follows: sections $2 \mathrm{a}, 2 \mathrm{~b}$, and $2 \mathrm{c}$ describe the CUGN observations, the CASE, and ancillary observations, respectively; sections $3 \mathrm{a}, 3 \mathrm{~b}$, and $3 \mathrm{c}$ detail the comparison of CASE with SSH analyses, independent CalCOFI observations, and assimilated CUGN observations, respectively; section 4 summarizes the comparisons; and section 5 discusses the implications and applications of the results.

\section{Data and methods}

\section{a. Glider observations}

In the CUGN, buoyancy-driven Spray underwater gliders (Sherman et al. 2001) complete repeat sections along the inshore $350-500 \mathrm{~km}$ of CalCOFI lines $66.7,80$, and 90 (Fig. 1). The gliders provide long-term observations (2006 to present) with high spatial resolution by profiling the upper $500 \mathrm{~m}$ in a sawtooth pattern of consecutive dive cycles that are completed in $\sim 3 \mathrm{~h}$ and over $\sim 3 \mathrm{~km}$. The sensors on the glider platform [which are described in detail by Rudnick et al. (2017)] measure pressure, temperature, salinity, depth-dependent velocity, acoustic backscatter, and chlorophyll fluorescence during each ascent. Depth-averaged velocity $(0-500 \mathrm{~m})$ is computed via dead reckoning between successive GPS position fixes (Davis et al. 2008; Todd et al. 2009).

CUGN temperature, salinity, and depth-averaged velocity data are processed into a regional climatology that gets updated monthly as near-real-time data continue to stream in. For each variable along each line, the climatology consists of the mean field, annual cycle, and interannual anomaly from the annual cycle. As detailed by Rudnick et al. (2017), the mean and annual cycle maps are produced by a least squares fit and the anomaly maps by an objective analysis. The temperature, salinity, and depth-averaged velocity gridded products are calculated directly from CUGN data; then additional fields such as potential density and geostrophic velocity are derived from the maps.

\section{b. Numerical state estimate}

The CASE is a regional implementation of the MITgcm (Marshall et al. 1997a,b) and the Estimating 
the Circulation and Climate of the Ocean (ECCO) 4D-Var assimilation system (Stammer et al. 2002). The first guess ("prior") model solution of the CASE state estimation is a forward model simulation (forecast) initialized from the Hybrid Coordinate Ocean Model (HYCOM; Chassignet et al. 2007) global reanalysis and forced with the National Centers for Environmental Prediction-National Center for Atmospheric Research (NCEP-NCAR) Reanalysis Project (Kalnay et al. 1996) atmospheric state. The HYCOM global $(1 / 12)^{\circ}$ daily analysis uses the Navy Coupled Ocean Data Assimilation (NCODA; Cummings 2005) (https:// hycom.org/dataserver/gofs-3pt0/analysis) to assimilate a variety of global and regional ocean datasets, including the CUGN, and shows skill in reproducing these observations. However, frequent (daily) increments of HYCOM lead to discontinuities in its property and momentum balances. CASE uses HYCOM analysis to initialize the first-guess solution of the state estimation. It produces nonoverlapping 3-month state estimates of the ocean state with closed budgets, the goal of which is to provide a science resource where the simulated evolution of the hydrography can be explicitly interpreted.

The MITgcm integrates the Navier-Stokes equations on a sphere under the Boussinesq approximation. The equations are written in $z$ coordinates and discretized using third-order direct space and time approximation in a staggered Arakawa $\mathrm{C}$ grid. The numerical code of the MITgcm is designed to enable computer generation of its adjoint model using the automatic differentiation tool Transformations of Algorithms in Fortran (TAF; Giering and Kaminski 1998; Heimbach et al. 2002). The CASE domain extends from $27^{\circ}$ to $40^{\circ} \mathrm{N}$ and from $130^{\circ}$ to $114^{\circ} \mathrm{W}$ and is integrated on a $(1 / 16)^{\circ} \times(1 / 16)^{\circ}(\sim 8 \mathrm{~km})$ spherical polar grid, with 72 vertical $z$ levels. Model open boundary and initial conditions are from the HYCOM global $(1 / 12)^{\circ}$ daily analysis (for the period 2009-17; https://hycom.org/ dataserver/gofs-3pt0/analysis) and (1/12) ${ }^{\circ}$ daily reanalysis (for the period 2007-08; https://hycom.org/dataserver/ gofs-3pt0/reanalysis), which are closer to the observations than the final state of the previous 3-month assimilation. HYCOM solutions sampled at 7-day intervals are spatially interpolated onto the model grid and specified along the open boundary. The model solutions are relaxed to HYCOM open boundary conditions within a buffer zone of $0.8^{\circ}$ over time scales varying linearly from 5 days at the boundary to 10 days at the inner edge of the buffer zone. The projected HYCOM normal velocities across the open boundary have been adjusted to have zero net volume flux into the domain. The model uses the bulk formulation (Large and Pond 1981) for the computation of the atmospheric fluxes, and the NCEP-NCAR reanalysis forcing fields are sampled every $6 \mathrm{~h}$ on a spatial grid of $2^{\circ} \times 2^{\circ}$. Monthly climatological runoff fluxes from the
ECCO global model (Stammer et al. 2002) are used in this model.

The MITgcm-ECCO 4D-Var assimilation system minimizes a "cost function" that penalizes the weighted sum of squared misfits between model and observations plus weighted sum of squared control adjustments during a specified period of time (assimilation window) by using the adjoint model to adjust the control variables (Wunsch 1996). The control vector consists of model initial conditions for temperature and salinity, all atmospheric forcings, and temperature, salinity, and horizontal velocity fields at the open boundaries. The gradient of the cost function is obtained by integrating the adjoint of the tangent linear model backward in time (Ledimet and Talagrand 1986) and is used with the quasi-Newton M1QN3 conjugate-gradient algorithm (Gilbert and Lemaréchal 1989) to adjust the control variables to iteratively descend the cost function toward the minimum. The CASE solutions are available online (http://www.ecco.ucsd.edu/case.html).

For consistency, the CASE output is processed like the glider data to produce numerical mean, annual cycle, and anomaly fields like those of the CUGN climatology. However, unlike the irregularly spaced three-dimensional glider data, the CASE output fields are four-dimensional and uniformly gridded in space and time, so the mapping method is adapted accordingly. First, mean fields and annual cycles are computed for the following variables: potential temperature, salinity, and zonal, meridional, and vertical velocity. As in the glider method (Rudnick et al. 2017), a least squares fit of seven temporal functions (a constant and the first three annual harmonics of sine and cosine) is calculated over the base period of 2007-13. Unlike the glider method, the fits are calculated independently at each grid point with no binning, weighting, or smoothing across grid points. The result of the fit is a set of coefficients for the seven functions for each variable at each grid point, which can be evaluated at any exact time to construct the mean and annual cycle fields. Assuming a diagonal data error covariance matrix with unit variance, the error covariance of the harmonic fit coefficients is relatively small (i.e., $\sim 0.004$ for the mean and $\sim 0.008$ for the first three annual harmonics of sine and cosine). For example, a 0.1-psu RMS salinity error in the CASE output propagates into a 0.002 -psu RMS error in the constant coefficient of the harmonic fit and a 0.003-psu RMS error in any of the annual harmonics. These low uncertainties are due to the model's high temporal resolution (daily). Second, the anomaly fields are calculated by removing the mean and annual cycle fields from the CASE output. As needed throughout this comparative analysis, these fourdimensional CASE mean, annual cycle, and anomaly products are spatially interpolated to the glider lines and 
depth bins and used to calculate derived fields such as potential density and geostrophic velocity.

\section{c. Ancillary observations}

\section{1) WiTHHELD OBSERVATIONS}

Temperature and salinity observations from CalCOFI cruises were withheld from assimilation into the CASE and are used as independent observations to assess the quality of the state estimate. Observations at CalCOFI stations from all 2007-17 cruises (except two that were unavailable during January-June 2009) are compared with control ("first guess") and optimized model solutions for every 3-month assimilation experiment. The cruise tracks varied, with some doing extra stations on top of the regular stations occupied since 1984. The depth-averaged glider velocities from CUGN were also withheld from assimilation into the CASE and are used for independent model verification.

\section{2) Assimilated observations}

The CASE assimilated a variety of observations from local and remote sensors, sampling both the ocean surface and the water column. Along-track SSH from satellites Jason-1, Jason-2, Envisat-1, CryoSat-2, and Satellite with Argos and AltiKa (SARAL)/“AltiKa" (Ka-band altimeter) were obtained from the Radar Altimetry Database System (RADS; http://rads.tudelft.nl/rads/rads. shtml). The time-mean dynamic ocean topography was the difference between the Danish National Space Center Mean Sea Surface 2008 (DNSCMSS08) and Earth Gravity Model 2008 (EGM08): DNSCMSS08-EGM08 (Andersen and Knudsen 2009; Pavlis et al. 2012). SSH observations were bin averaged daily onto the model grid, partitioned into time mean and anomaly components over the assimilation window, and separately fit using different uncertainties. In the SSH cost function, the uncertainty for the time-mean SSH is $5 \mathrm{~cm}$, approximately that of the mean geoid in our study domain (Mazloff et al. 2014), and the uncertainty for the anomaly SSH constraint is $3 \mathrm{~cm}$, approximately that of the Jason class altimeters. The SSH cost separation removes the geoid error component from the anomaly. Sea surface temperature (SST) data were obtained from the daily optimally interpolated product derived from the Tropical Rainfall Measuring Mission's (TRMM) Microwave Imager (TMI) and the Advanced Microwave Scanning Radiometer for the Earth Observing System (AMSR-E) instruments produced by Remote Sensing Systems, Inc. (http://www. remss.com/). SST observations on a $1 / 4^{\circ} \times 1 / 4^{\circ}$ grid were interpolated onto the model grid prior to assimilation but used with increased observational uncertainties to account for the redundant observations. Depth-binned temperature and salinity profiles were obtained from the CUGN (https://spraydata.ucsd.edu/projects/CUGN), and Argo temperature and salinity profiles were obtained from the USGODAE Argo data server (http://www.usgodae.org/ argo/argo.html). Argo "Delayed mode: D" profiles, which have been subjected to detailed scrutiny by oceanographic experts, were used in the study. The following data were also assimilated: repeat high-resolution expendable bathythermograph (XBT) temperature transects obtained from the Scripps Institution of Oceanography XBT network site (http://www-hrx.ucsd. edu/index.html), the autonomous pinniped bathythermograph (APB) temperature profiles obtained from NCEI (http://www.ncei.noaa.gov/), and shipboard CTD profiles from the CLIVAR and Carbon Hydrographic Data Office (CCHDO) data server (https://cchdo.ucsd.edu/).

\section{State estimate evaluation}

\section{a. Comparison with SSH analyses}

The gridded AVISO SSH analysis is compared with CASE persistence (no time evolution, keeping initial state fixed), control (first guess), and optimized solutions and with HYCOM global daily analysis (Fig. 2). The SSALTO/Data Unification and Altimeter Combination System (DUACS) altimeter product AVISO is produced and distributed by the Copernicus Marine and Environment Monitoring Service (CMEMS) (http:// marine.copernicus.eu/) and is widely used as a benchmark for SSH comparison. The first guess amounts to a 3-month forward model simulation (forecast) initialized from HYCOM analysis, and the solution does drift out of consistency with observations eventually (Fig. 2). Some of the SSH error in our prior (first guess) solution is due to the coarse resolution and biases in NCEPNCAR reanalysis atmospheric forcing. Another reason for the drift is the hard constraint for physical budget closure over the 3-month assimilation window, through which we sacrifice controllability of the solution. Though we have optimized over the 3-month assimilation window, the final state (end of 3-month window) is less consistent with SSH observations than the HYCOM reanalysis, which has more frequent (daily) updates and stays closer to the observations. This motivates initialization of the state estimate from HYCOM rather than the final state of the previous 3-month assimilation cycle. A shorter window would allow more control over the final state, but would reduce the effects of forcing and model dynamics compared to initial conditions. The control solution's rate of error increase is lower than that of persistence, and the final misfits of this unoptimized forecast are only about 2 times the expected residuals, 


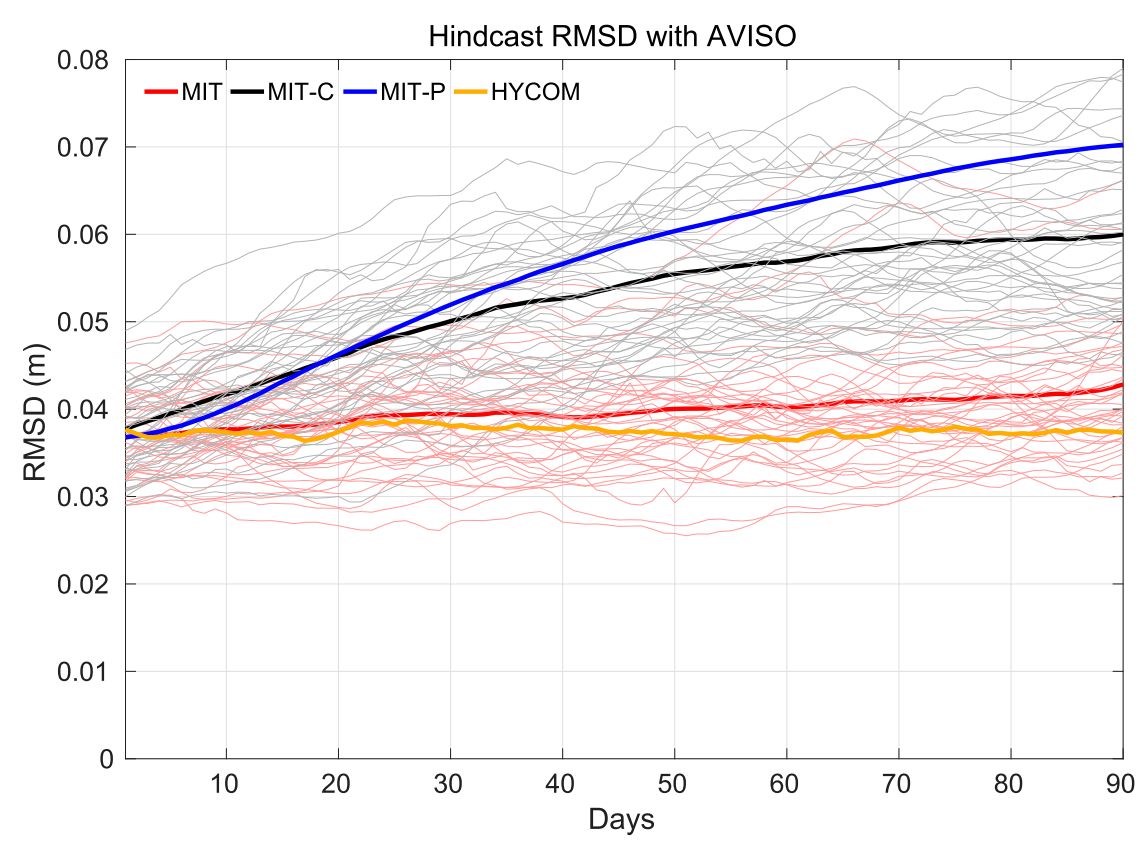

FIG. 2. RMSD between AVISO and CASE optimized solutions (red), CASE control solutions (black), CASE persistence solutions (blue), and the HYCOM global daily analysis (gold). Thin lines are the RMSD between AVISO and CASE control solutions (gray) and AVISO and CASE optimized solutions (red) stacked for every 3-month state estimation realization. Thick colored lines are RMSD composites averaged over all 3-month realizations.

which is a validation of both the HYCOM initialization and the CASE model. The 4D-Var assimilation brings the solution back to being almost as close to the AVISO analysis as HYCOM, which is a validation of the linearity of the adjoint assimilation. If nonlinearities dominated the model evolution over the 3-month assimilation windows, the adjoint method would not be able to reduce the cost function. This SSH comparison shows that CASE starts from a good analysis as a prior (HYCOM) and improves upon it to derive an optimal solution that is both consistent with observations and dynamics over a time range where persistence is not a good forecast, meaning that the dynamics and forcing are important. This longer time range comes at a cost of smoothing out small scales and underestimating currents, which will be discussed in subsequent sections.

\section{b. Comparison with withheld observations}

Observed and modeled time- and depth-averaged velocity fields capture the poleward California Undercurrent (CU) and the equatorward California Current (CC) (Fig. 1a). Along lines 66.7 and 80, the horizontal shear between the CU and CC is high with a clear intercept location at which the alongshore velocity is zero. The observed and modeled zero crossings are collocated at roughly 150 and $115 \mathrm{~km}$ offshore along lines 66.7 and 80 , respectively. Along line 90, the alongshore flows are weaker. Within the Southern California Bight (SCB), shallow bathymetry controls observed and modeled $\mathrm{CU}$ pathways. For both the across-shore and alongshore mean velocity components, the root-mean-square difference (RMSD) between the model and observations RMSD $_{\text {model-CUGN }}$ is $0.01 \mathrm{~m} \mathrm{~s}^{-1}$ when computed over all three glider lines. CASE reveals meanders, recirculation patterns, and flow continuity that cannot be resolved by the CUGN sampling pattern. Permanent meanders of the broad CC (Centurioni et al. 2008) and cyclonic recirculation eddies between the CC and CU (Lynn and Simpson 1987, 1990) are known physical features of the CCS. Figure 1a indicates that CASE realistically resolves the horizontal structure of the regional velocity field along the glider lines, corroborating the findings of Todd et al. (2011b), and exhibits smooth dynamical interpolation in between.

The CalCOFI temperature and salinity observations were compared against the 3-month state estimates and control solutions over 2007-17. The state estimate and control solutions were spatially and temporally interpolated to the CalCOFI observation locations within each 3-month assimilation window. The RMSD model-CalCOFI $_{\text {and }}$ $\mathrm{RMSD}_{\text {control-CalCOFI }}$ for 50-m temperature and 80-m salinity are shown in Fig. 3. The RMSD model-CalCOFI $_{\text {is consis- }}$

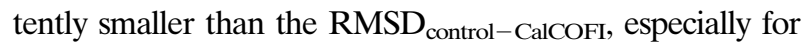
temperature, except during the 2007-08 period. This is likely because during this time the control solutions take initial 


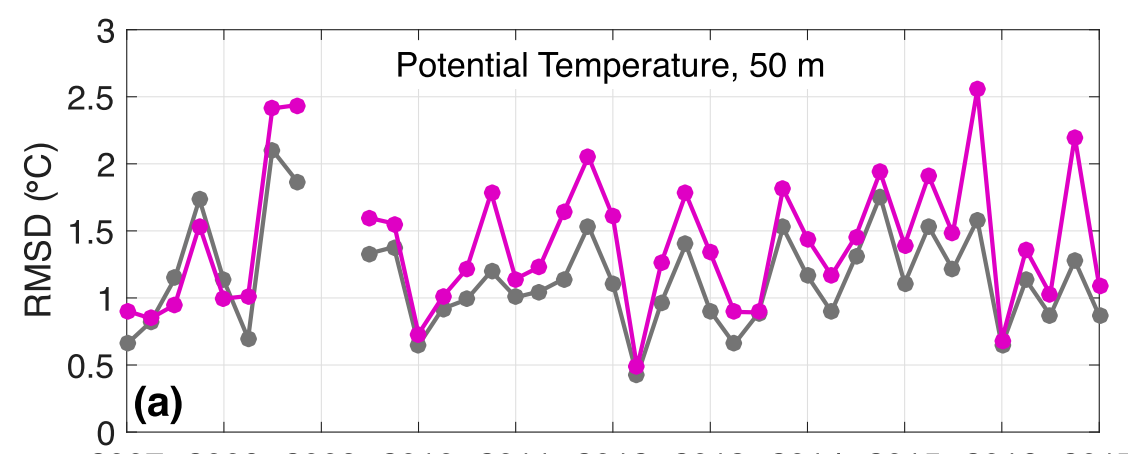

20072008200920102011201220132014201520162017

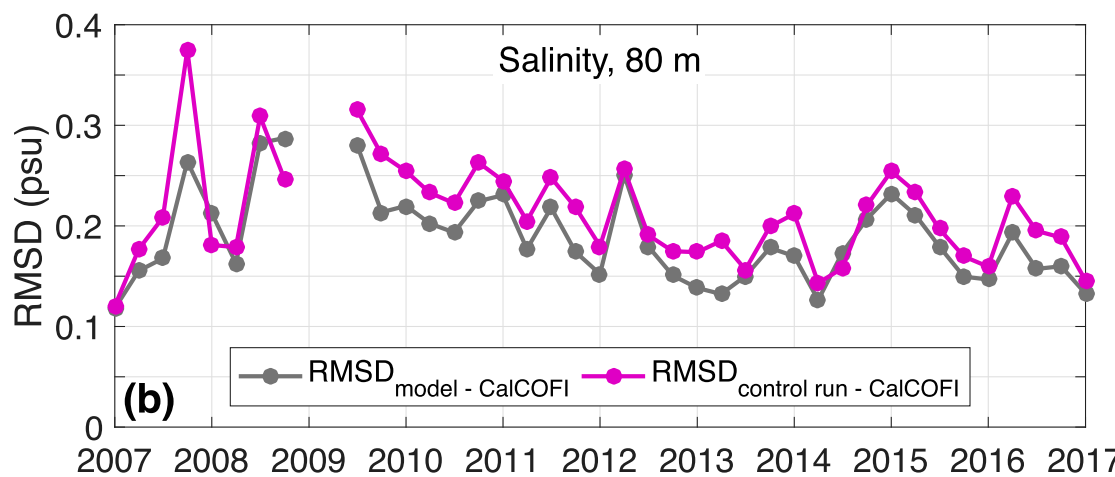

FIG. 3. RMSD between CASE and CalCOFI (a) 50-m potential temperature and (b) 80-m salinity plotted for each assimilation window. Purple lines represent the initial control run of CASE, and gray lines represent the final run of CASE.

conditions and open boundary conditions from the $(1 / 12)^{\circ}$ HYCOM/NCODA global daily reanalysis, which differs from the $(1 / 12)^{\circ} \mathrm{HYCOM} / \mathrm{NCODA}$ daily analysis that is used for the rest of the experiments (2009-17) but was not available before 2009. HYCOM had lower skill during 2007-08, which had cascading effects on the quality of the CASE control run, as well as the model's ability to propagate observational constraint information and to attain an optimal fit to the independent CalCOFI data during that time period. When summed over all depths, the $\mathrm{RMSD}_{\text {model-CalCOFI }}$ was generally smaller than at these selected depths.

To assess the model skill in propagating information between glider lines, $50-\mathrm{m}$ temperature and $80-\mathrm{m}$ salinity CalCOFI measurements from all 2007-17 cruises were binned and compared with CASE optimized and control solutions. The model skill improvement, sometimes referred to as skill score (Murphy 1992; Oke et al. 2002), is defined as 1 - ( $\left.\mathrm{MSD}_{\text {model-CalCOFI }} / \mathrm{MSD}_{\text {control-CalCOFI }}\right)$ and shown for temperature and salinity in Fig. 4, where bins with a minimum of 20 data points were considered in the analysis. CASE shows positive skill improvement onshore, especially near the coast, and decreased skill improvement offshore along the CalCOFI lines for both temperature and salinity. CASE shows more skill improvement for temperature than salinity. CASE also shows slightly more skill improvement along line 80 and 90 relative to other across-shore lines for salinity, which were sampled extensively by CUGN.

The model bias and standard deviation of temperature (Fig. 5a) and salinity (Fig. 5b) are shown as a function of depth for 0-500 m. Relative to CalCOFI, CASE temperatures between 0 and $75 \mathrm{~m}$ show a warm bias up to $\sim+1^{\circ} \mathrm{C}$ in the control solution and $\sim+0.4^{\circ} \mathrm{C}$ in the optimized solution (Fig. 5a). Both solutions show a comparable cold temperature bias $\left(\sim-0.1^{\circ} \mathrm{C}\right)$ in the depth range $75-500 \mathrm{~m}$. CASE salinity is biased high above $170 \mathrm{~m}$ (up to $+0.8 \mathrm{psu}$ ) and slightly low (fresh) below that ( -0.15 psu) (Fig. 5b). The CASE improves over 0-50-m salinity, although the percentage reduction in bias is lower than for temperature. The standard deviation of modeldata misfit indicates how well CASE captures the overall variance of the CalCOFI observations. The disagreement is highest at depths with elevated vertical gradients, that is, near the thermocline at $50 \mathrm{~m}$ (Fig. 5a) and the halocline at 80-100 $\mathrm{m}$ (Fig. 5b). Figures $5 \mathrm{a}$ and $5 \mathrm{~b}$ also show that CASE underestimates the variance of CalCOFI temperature and, even more so, salinity at those depths. This underestimation of variance in CASE could be due to its weaker vertical salinity gradients over $0-170 \mathrm{~m}$ (Fig. 5b), 

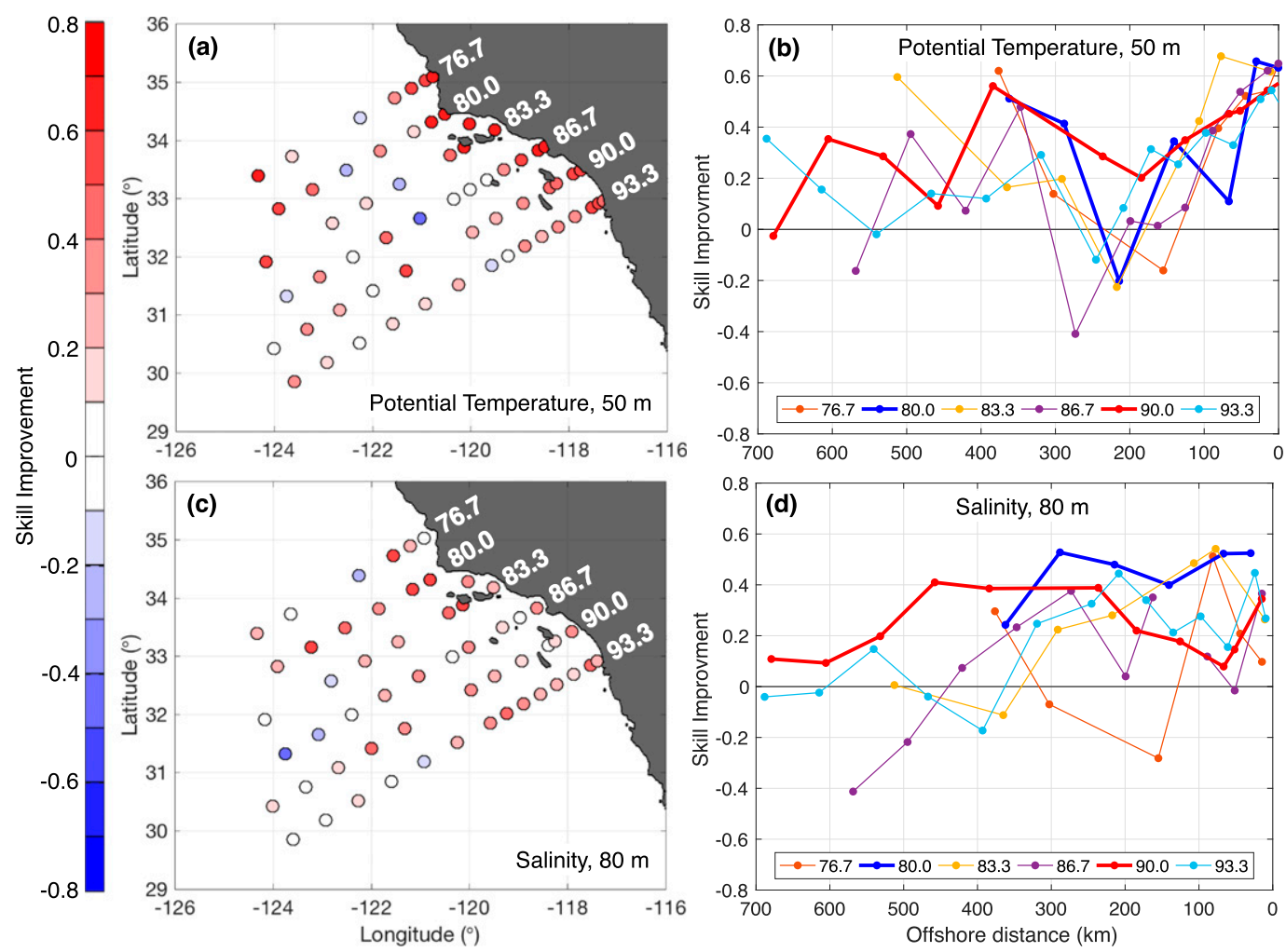

FIG. 4. Skill improvement in the CASE fit to CalCOFI with respect to the control-run fit for (a),(b) 50-m potential temperature and (c),(d) 80-m salinity. The skill improvement at each location is calculated as $1-\left(\mathrm{MSD}_{\text {model-CalCOFI }} /\right.$ $\mathrm{MSD}_{\text {control run-CalCOFI}}$ ). Comparisons are plotted only for CalCOFI locations with 20 or more casts.

and the consequent weaker contribution of isohaline heave to local salinity variance.

\section{c. Comparison with assimilated glider observations}

\section{1) MEAN}

We compare mean fields from the CASE and CUGN climatologies to assess the model's representation of broad horizontal thermohaline structures (Figs. 1b-d) and its spatially interpolated output along the glider sections (Figs. 6 and 7). We focus the comparison on the potential temperature and salinity state variables, as well as the derived potential density and geostrophic velocity fields. Overall, CASE reproduces the mean temperature field well but underestimates mean acrossshore salinity gradients and isopycnal slopes.

In the CCS, isotherms, isohalines, and, consequently, isopycnals slope upward toward the coast, as is characteristic of eastern boundary upwelling systems. This persistent, large-scale thermohaline structure is maintained by the mean vertical and horizontal transports of distinct water masses. Locally and remotely wind-driven upwelling drives the vertical displacement of cold, salty, dense water from depth toward the surface, resulting in a negative isobaric potential temperature gradient (Fig. 1b), a positive isobaric salinity gradient (Fig. 1c), and isopycnal shoaling (Fig. 1d) toward the coast.

At 50-m depth, observed mean potential temperature values are hardly distinguishable from the full model field (Fig. 1b). The 50-m isobar is shown because it is roughly the depth of the thermocline, and we will repeatedly refer to it throughout the paper. Temperature variability at $50-\mathrm{m}$ depth is largely driven by vertical displacements of the thermocline, making it an interesting and relevant isobar to monitor as its temperature fluctuations represent an important mechanism of physical variability. By the same reasoning, the strong vertical temperature gradient makes it challenging to model the temperature structure and variance near $50-\mathrm{m}$ depth, as indicated by the peaks in model-data offset $\left(\sim+0.5^{\circ} \mathrm{C}\right)$ and standard deviation around $50 \mathrm{~m}$ (Fig. $\left.5 \mathrm{c}\right)$. In showing realistic horizontal temperature structure (Fig. 1b) along an isobar with a minimum in model skill, we infer that CASE realistically resolves temperature structure throughout the water column.

At 80-m depth, the observed and modeled mean salinity fields show better agreement nearshore than offshore (Fig. 1c). The coastal salty signatures of upwelling 

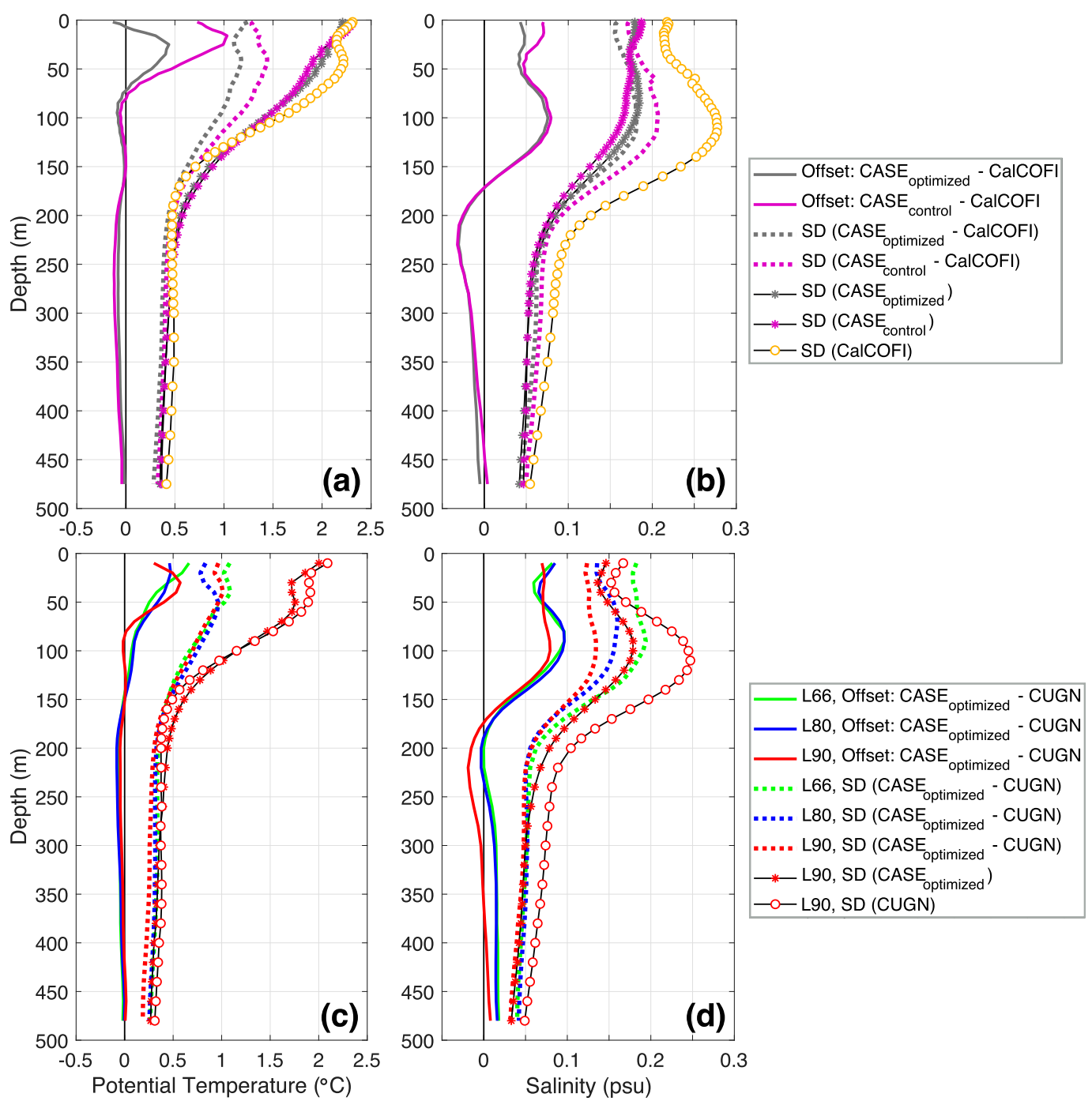

FIG. 5. Depth-dependent offset calculated as model minus data (solid lines), standard deviation (label "SD") of model-data misfit (dotted lines), SD of model (asterisks), and SD of observations (circles). The metrics are computed for (a),(c) potential temperature and (b),(d) salinity over 2007-17. Shown are comparisons of (top) CASE and CalCOFI (where purple is the CASE initial control solution, gray is the CASE optimized solution, and gold is the CalCOFI data) and (bottom) the CASE optimized solution and CUGN along CalCOFI lines 66.7 (green), 80 (blue), and 90 (red). For visual clarity in (c) and (d), profiles of SD(CASE optimized $_{\text {) }}$ and SD(CUGN) are only shown for line 90 , although they exhibit similar vertical structure for lines 66.7 and 80 (not shown).

and the $\mathrm{CU}$ are apparent, as is the fresh core of the equatorward CC. While the modeled across-shore salinity gradient has the correct sign, its magnitude is weaker than that of the glider observations. At the offshore extent of the lines, the CASE salinity values are several tenths of a practical salinity unit greater than the observed values, indicating a positive salinity bias within the modeled CC. This bias could be due to weak model circulation, which cannot maintain a sufficiently strong salinity gradient if the low-salinity CC is too slow to overcome diffusion. The average depth of the halocline inshore of $200 \mathrm{~km}$ is $80 \mathrm{~m}$, where the model salinity bias is positive $(+0.075-0.1 \mathrm{psu})$ and salinity variance is underestimated (Fig. 5d), relative to CUGN observations. Because the nearshore salinity variability at $80-\mathrm{m}$ depth is dominated by vertical displacements of the halocline, we will refer to it throughout the paper when diagnosing upwelling and downwelling anomalies, necessitating the display of its mean horizontal salinity structure up front. Overall, the state estimate captures the mean structure and gradient directions of the salinity field; however, it shows relatively less realism in the offshore region of the CC and within the depth range of the halocline. 

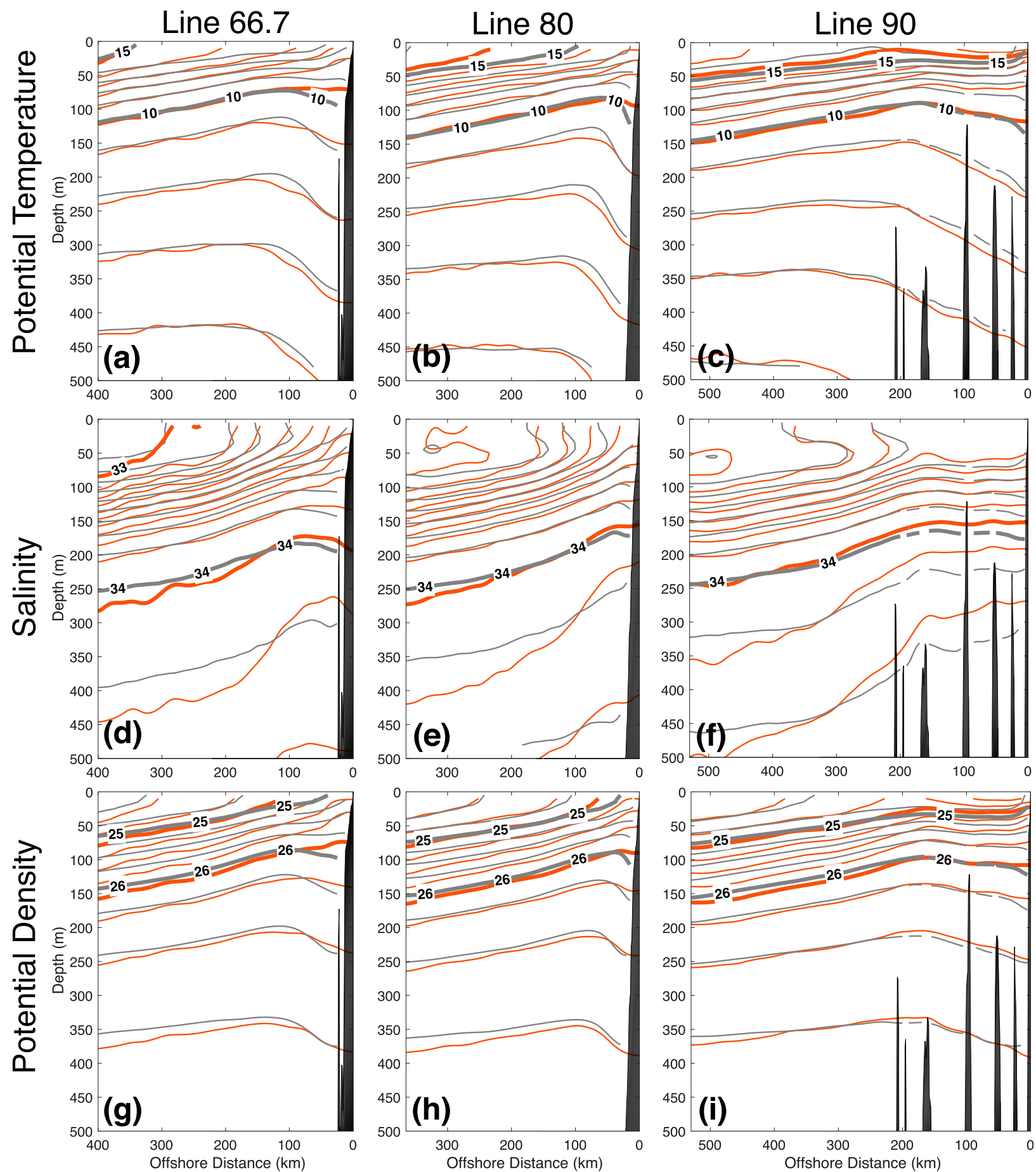

FIG. 6. Time-mean (2007-13) sections of (a)-(c) potential temperature, (d)-(f) salinity, (g)-(i) potential density along lines (left) 66.7, (center) 80.0, and (right) 90.0. Glider-measured values are shown in orange contours, and interpolated model values are shown in gray contours. The contour intervals are $1^{\circ} \mathrm{C}$ for potential temperature, $0.1 \mathrm{psu}$ for salinity, and $0.25 \mathrm{~kg} \mathrm{~m}^{-3}$ for potential density. The labeled thick contours are the $10^{\circ}$ and $15^{\circ} \mathrm{C}$ isotherms for (a)-(c), the 33- and 34-psu isohalines for (d)-(f), and the 25 and $26 \mathrm{~kg} \mathrm{~m}^{-3}$ isopycnals for (g)-(i). Black shading masks bathymetry. 

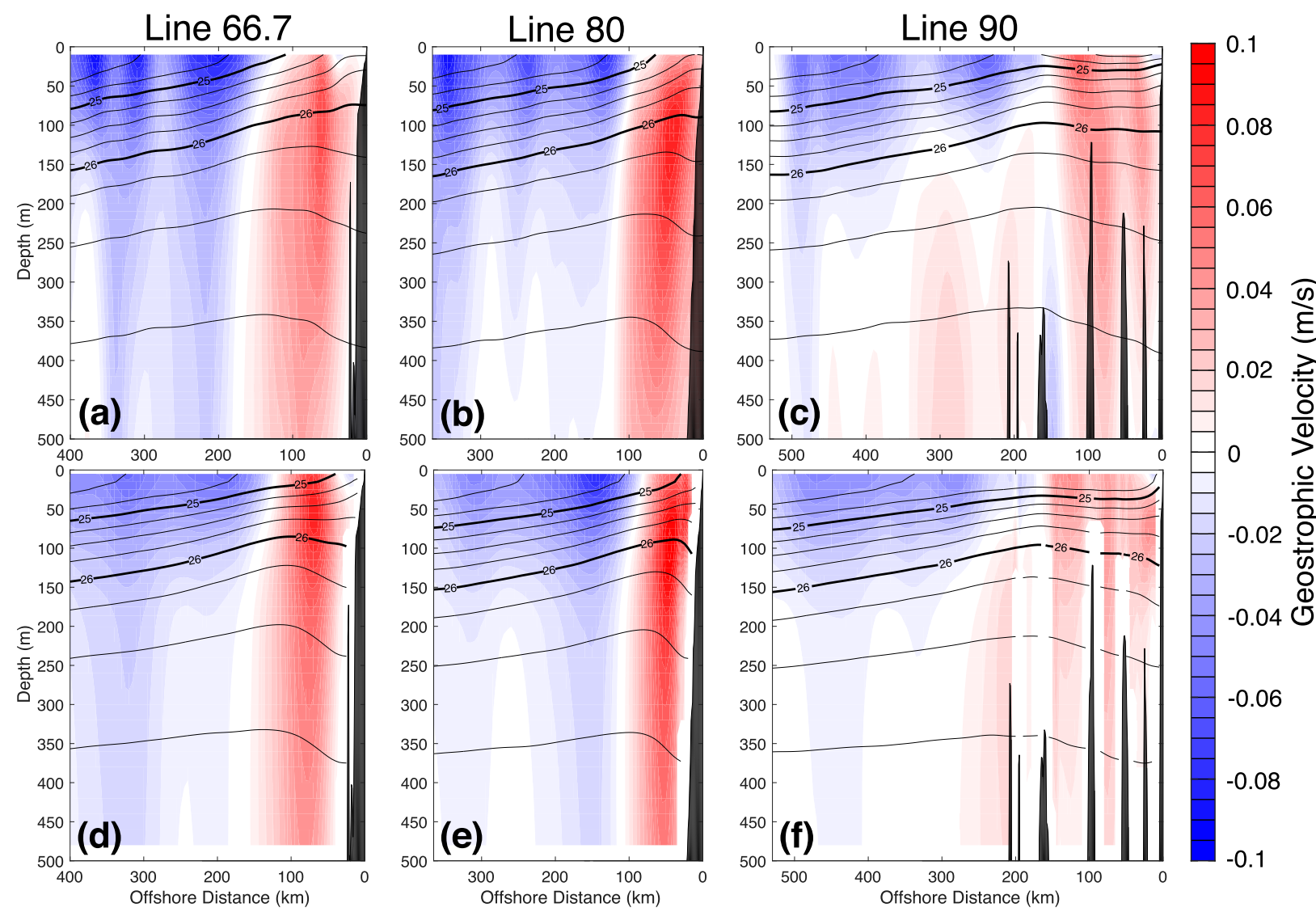

FIG. 7. Time-mean (2007-13) sections of (a)-(c) glider-measured and (d)-(f) modeled geostrophic velocity across lines (left) 66.7, (center) 80, and (right) 90. Geostrophic velocity is shown in color-filled contours, where red is poleward and blue is equatorward, potential density is contoured in black, and black shading masks the bathymetry.

The dynamics of the CCS may be examined through isopycnal depth structure. The sign of modeled isopycnal slopes matches that of the observations, with the isopycnals shoaling toward the coast (Fig. 1d). Like the salinity field, the agreement between observed and modeled mean $26.0 \mathrm{~kg} \mathrm{~m}^{-3}$ isopycnal depth is better at the nearshore extent of the lines than offshore (Fig. 1d). The $26.0 \mathrm{~kg} \mathrm{~m}^{-3}$ isopycnal lies just below the pycnocline. Offshore, the state estimate's shallow isopycnal depth bias is caused by the positive salinity bias of the CC. It could also be due to weak model circulation, which would correspond to flatter isopycnal slopes balancing subdued geostrophic currents. The RMSD model-CUGN $26.0 \mathrm{~kg} \mathrm{~m}^{-3}$ isopycnal depth over all three sections is approximately $8 \mathrm{~m}$.

The CASE captures the major features of the mean depth-dependent thermohaline structure, including the positions of strong vertical gradients and the isoline slopes (Fig. 6). In the upper $100 \mathrm{~m}$ along lines 66.7 and 80 , observed and modeled isotherms (Figs. 6a,b), isohalines (Figs. 6d,e), and isopycnals (Figs. 6g,h) deepen monotonically with offshore distance. Along line 90, the isolines are flat or shoaling with offshore distance within the SCB $(0-200 \mathrm{~km})$ and then deepening monotonically west of the bight (Figs. 6c,f,i). This isoline doming above the Santa Rosa Ridge could be caused by localized mixing (Johnston and Rudnick 2015) or upwelling in the center of the cyclonic Southern California Eddy (Lynn and Simpson 1990). Below the pycnocline, isotherms and isopycnals along all three lines deepen near the coast revealing the presence of the relatively warm poleward CU in thermal wind balance. Isohalines continue to shoal to within $0-100 \mathrm{~km}$ of the coast, representing the combined effects of upwelling and the transport of a relatively salty water mass by the coastal CU. Last, CASE resolves the subsurface salinity minimum along line 90 (Fig. 6f) (and to a lesser extent along line 80; Fig. 6e), which suggests salinification by surface evaporation above the fresh CC core at this southern portion of the domain. All in all, the state estimate reproduces the essential components of the mean thermohaline structure in the upper $500 \mathrm{~m}$.

We identify areas where the observed and modeled contours do not overlay one another. Below the $10^{\circ} \mathrm{C}$ 
isotherm, the modeled isotherms lie shallower than the observed isotherms (Figs. 6a-c), revealing a slight cold bias in mean CASE temperature below the thermocline. Above the $10^{\circ} \mathrm{C}$ isotherm, observed and modeled isotherms match up at the offshore extent of the lines but diverge nearshore with modeled isotherms below observed isotherms, revealing a slight warm bias in the mean CASE temperature above the thermocline. Realistic surface forcing is needed to accurately resolve upper-ocean temperatures, and these results suggest that the surface heat gain in the model is too high.

As in Fig. 1c, the magnitude of across-shore isobaric salinity gradients is underestimated in CASE. Observed isohaline slopes are steeper in the observations than in the model, a discrepancy that is especially apparent along isohalines saltier than 34 psu (Figs. 6d-f). Salinity in CASE is positively biased offshore and negatively biased nearshore; thus the across-shore salinity gradient is weaker than that of the observations. Potential density exhibits some of the same problems as salinity. As with the isohalines, many of the modeled isopycnals are shallower than the equivalent observed isopycnal at the offshore extent of the line, causing the slope of modeled isopycnals to be biased low. Nearshore and near the surface, the modeled isopycnals show a deep bias such that less of the deep dense water is reaching the surface and isopycnal outcrop locations are closer to shore, relative to glider-measured means. The large-scale thermohaline structure is generally reproduced by CASE, and we do not expect a perfect matchup between the CASE and the assimilated glider observations.

Geostrophic velocity is derived as the thermal wind shear from along-section density gradients referenced to the across-section depth-averaged velocity. CASE does not assimilate this derived velocity, although the assimilation of temperature and salinity implies that the CASE velocity shear is improved by the CUGN. CASE accurately represents the location and magnitude of the deep poleward CU nearshore and the shallow equatorward CC offshore (Fig. 7). However, CASE's representation of the second poleward CU core along line 90 (Fig. 7f) is narrower and weaker than the observed CU (Fig. 7c). The deep offshore CU core is a known feature of the regional circulation along line 90 and was previously measured by shipboard ADCP (Gay and Chereskin 2009), in the CUGN (Davis et al. 2008) and simulated in a previous version of CASE (Todd et al. 2011b). Relative to Todd et al. (2011b), the second CU core presented here is narrower and deeper, though differences should be expected as the base period for the mean calculation changed from 2007-09 to 2007-13. Furthermore, there are three cores of near surface, equatorward flow along lines 66.7 and 80 in the observed mean (Figs. 7a,b) and some weaker cores in CASE (Figs. 7d,e). Rudnick et al. (2017) speculated that these cores are imprinted upon the observed mean through glider subsampling of an annual cycle in the CC's position or an eddy-rich velocity field.

\section{2) Annual cycle}

On an annual time scale, surface fluxes and winddriven upwelling dictate thermohaline variability. Thus, an assessment of the modeled potential temperature, salinity, and potential density annual cycles is, by proxy, an assessment of the air-sea fluxes and wind fields that force the model at the surface boundary. Within each 3-month assimilation window, property evolution is directly determined by the model dynamics as controlled by initial state, lateral boundary conditions, and atmospheric fluxes. In the CUGN region at the center of the CASE model domain, an evaluation of CASE variability within an assimilation window is primarily an evaluation of the model physics and the optimized fluxes. The growth of error in the persistence forecasts quantifies the influence of the forcing and dynamics. Climatologically, air-sea heat and salt fluxes are downward in the summertime, creating warm, salty, highly stratified surface waters. Upper-ocean heat content and salt peak in early fall when this period of downward fluxes ends. Approximately $90^{\circ}$ out of phase, wind-driven upwelling is strongest in the spring and early summer, driving the vertical transport of cold, salty, dense water from depth toward the surface. The CASE annual cycles capture these dominant signals (Fig. 8). Here we provide a detailed comparison of the CASE annual cycles to those of the CUGN climatology, a critical component of our overall assessment since these annual cycles are the baseline for calculating the CASE anomaly fields.

Within the upper $50 \mathrm{~m}$, CASE resolves the thermohaline variability associated with surface heat and salt fluxes. From late summer through fall, increased thermal and density stratification is made apparent by tightly packed potential temperature (Figs. 8a-c) and potential density (Figs. 8g-i) contours near the surface. However, modeled September surface temperatures are $1^{\circ}-3^{\circ} \mathrm{C}$ warmer than observed temperatures and the thermal and density stratification over $0-50 \mathrm{~m}$ is stronger. This positive bias in modeled surface temperature and upperocean stratification suggests that heat input from the atmosphere to the ocean is also biased high during the late summer and early fall. Differences in observed and modeled horizontal heat advection via the poleward $\mathrm{CU}$ or offshore Ekman transport could also be factors in the model's bias. 

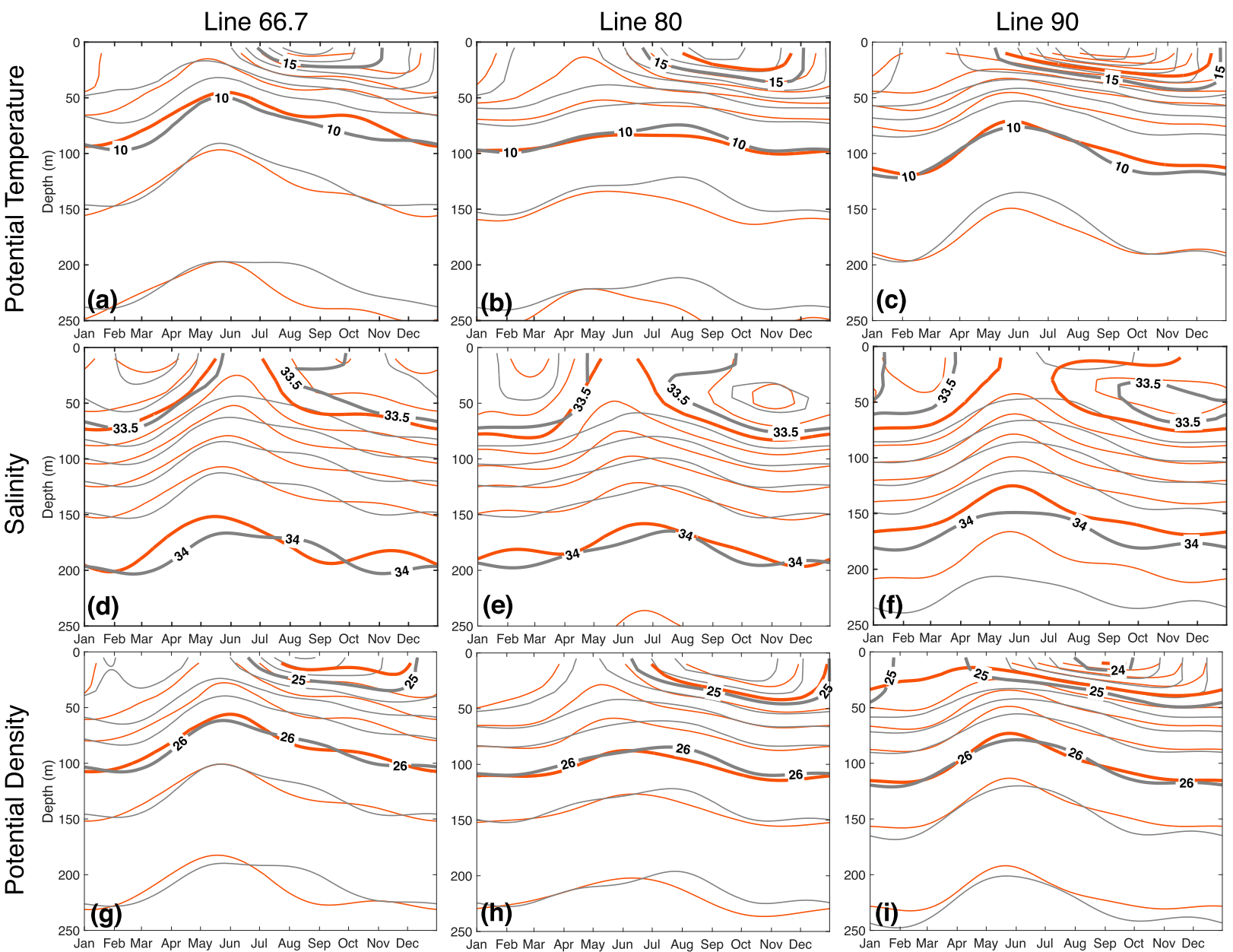

FIG. 8. Annual cycles of (a)-(c) potential temperature, (d)-(f) salinity, (g)-(i) potential density plotted as a function of time and depth (upper $250 \mathrm{~m}$ ). The fields are averaged over the inshore $150 \mathrm{~km}$ of lines (left) 66 and (center) 80 and $200 \mathrm{~km}$ of (right) line 90 . Glidermeasured values are shown in orange contours, and interpolated model values are shown in gray contours. The contour intervals are $1^{\circ} \mathrm{C}$ for potential temperature, $0.1 \mathrm{psu}$ for salinity, and $0.25 \mathrm{~kg} \mathrm{~m}^{-3}$ for potential density. The labeled thick contours are the $10^{\circ}$ and $15^{\circ} \mathrm{C}$ isotherms for (a)-(c), the 33.5- and 34-psu isohalines for (d)-(f), and the 24, 25, and $26 \mathrm{~kg} \mathrm{~m}^{-3}$ isopycnals for (g)-(i).

That time period is also one of maximum evaporation. The effects of evaporation are strongest along line 90, which runs through the SCB, where evaporation minus precipitation $(E-P)$ is likely greater than in the offshelf regions of the domain. Starting in July, a salinity inversion develops as excess $E-P$ creates a salty surface layer above a subsurface salinity minimum (Fig. 8f). This salty cap lasts through the end of the year and is resolved in the observed and modeled annual cycles alike. The salinity minimum is fresher in the observations than in the state estimate. To a lesser and shorter extent, this surface layer salinification is also apparent on line 80 (Fig. 8e). It is not apparent along line 66.7, suggesting that strongly positive $E-P$ does not occur along this northernmost line.

Isoline heave due to wind-driven upwelling is a clear feature of the CASE annual cycles along all three lines
(Fig. 8). In the spring and early summer, the upward displacement of isolines represents the transport of cold, salty, dense water from depth toward the surface. Observed and modeled isolines generally heave together in phase. At peak upwelling, most isolines are deeper in the CASE annual cycle than in the CUGN climatology, with the largest discrepancies contained in the salinity field as is apparent in the May-June depths of the 33.634-psu isohalines in Figs. 8d-f. In January, the observed and modeled isolines have the same depth; thus, the isoline depth discrepancy in spring indicates that CASE is underestimating seasonal vertical isoline excursions, which could be a contributing factor to CASE's underestimation of temperature and salinity variance near the depths of the thermocline and halocline (Figs. 5c,d). In other words, though the phase of nearshore isoline shoaling due to wind-driven upwelling is correct, its 
magnitude is biased low in CASE. The most likely culprit is the forcing wind field, which may underestimate wind stress and/or wind stress curl amplitude and, thereby, Ekman transport and Ekman suction, respectively. If the wind is too smooth or its resolution is too low, localized wind gradients and, thus, wind-driven upwelling strengths will be biased low.

Isopycnal analysis reveals that the two products agree qualitatively with respect to the seasonality of isopycnal heave and near-surface diapycnal mixing. Here we examine the $25.3 \mathrm{~kg} \mathrm{~m}^{-3}$ isopycnal because its mean depth is in the upper pycnocline and it falls within the mixed layer during parts of the year. Figures $9 \mathrm{a}-\mathrm{c}$ show the seasonal $25.3 \mathrm{~kg} \mathrm{~m}^{-3}$ isopycnal depth anomaly from the mean, whereby the isopycnal shoals during the spring and early summer and deepens during the fall and winter across an annual depth range that spans roughly $30 \mathrm{~m}$ in the $0-200-\mathrm{km}$ cross-shore average (Fig. 9c). Isopycnal displacement originates at the coast and propagates offshore, likely due to westward-propagating Rossby waves (Todd et al. 2011b). Along the inshore $200 \mathrm{~km}$ of line 90 , the $25.3 \mathrm{~kg} \mathrm{~m}^{-3}$ isopycnal has a mean depth of $44 \mathrm{~m}$ in the CUGN climatology and $50 \mathrm{~m}$ in CASE. During upwelling season, the $25.3 \mathrm{~kg} \mathrm{~m}^{-3}$ isopycnal's $20-\mathrm{m}$ displacement from the mean (Fig. 9c) brings it closer to the surface and well into the mixed layer, where it is no longer a material surface as it mixes with the relatively warmer water above. This drawdown of heat through wind-driven diapycnal mixing causes water parcels with a potential density of $25.3 \mathrm{~kg} \mathrm{~m}^{-3}$ to be warmer and, by compensation, saltier (Figs. 9d,e). Although it is about $50 \%$ weaker in magnitude and 1.5 months out of phase, CASE does resolve this isopycnal salinification (Figs. 9e,f) indicating that the numerical mixing parameterizations are representing mixing effects on isopycnal thermohaline variability. Along lines 66.7 and 80 , a similar isopycnal salinity signal is apparent in observations (Rudnick et al. 2017) and CASE resolves the signal there as well (not shown).

The observed semiannual cycle of nearshore geostrophic velocity (Figs. 10a-c) is also a feature of the state estimate (Figs. 10d-f). The nearshore spatial averages shown in Fig. 10 (0-150 or $0-200 \mathrm{~km}$ offshore, depending on the line) approximately span the width of the mean $\mathrm{CU}$ and therefore represent $\mathrm{CU}$ seasonal variability. There is a primary maximum in summer and a secondary maximum in winter, implying semiannual strengthening of the poleward CU across all lines. In the spring, an equatorward reversal of the surface flow occurs across all lines, as well as a weakening of the poleward flow at depth. Another weakening or reversal, depending on the line, occurs in the fall. There are a few discrepancies between the observed CU seasonal cycle and its representation in CASE. First, the velocity range is smaller in CASE than in the CUGN climatology (Fig. 10). The strength of the derived geostrophic velocity field is a function of horizontal density gradients (i.e., isopycnal slopes), which are weaker in the model than in the observations. Second, the modeled summertime poleward CU maxima lag the observed maxima by $1-2$ months along lines 66.7 and 90 , but there is no significant phase lag along line 80 . In a previous modeling study, Gómez-Valdivia et al. (2017) found that poleward-propagating coastally trapped waves caused the semiannual variability in the $\mathrm{CU}$.

\section{3) INTERANNUAL ANOMALIES}

Interannual anomalies in the CCS are in part the coastal imprint of basin-scale climate variability, for example, the ENSO cycle (Fiedler and Mantua 2017; Schwing et al. 2002). The CUGN climatology and CASE span the recent decade, during which the 2009-10 El Niño, the 2010-11 La Niña, and the 2015-16 El Niño occurred. In addition, an anomalous North Pacific marine heatwave occurred in 2014-15, whose connection to equatorial variability is being debated. Here we compare interannual anomaly fields from the CUGN climatology and CASE to determine whether CASE realistically reproduces the key physical anomalies associated with each of the four climate events listed above. The comparison focuses on depth-dependent temperature and salinity, as well as isopycnal depth and isopycnal salinity.

The CUGN and CASE 50-m interannual potential temperature anomalies are strongly correlated $\left(R^{2}>\right.$ 0.85) (Fig. 11). Though the observations (Figs. 11a,d,g) show more submesoscale to mesoscale structure than the smoother model output (Figs. 11b,e,h) in the Hovmöller plots, the key potential temperature anomaly signals are present in both products, most obviously the sustained 2014-16 warming along all three lines. The persistent warming was caused by two climate events, the 2014-15 marine heat wave and the 2015-16 El Niño, both of which brought distinct forcing to bear on the region. The warming anomalies are strongest along line 90 (Fig. 11i), the southernmost section. Both products show two distinct maxima at the peaks of the two events and an apparent lull in between. Along lines 66.7 and 80 , the warming also persists for 2.5-3 years, but there is less of a distinction between each event (Figs. 11c,f). A moderate El Niño had a warming effect at the turn of the year 2009/10 along line 90 (Figs. 11g-i) and, to a lesser extent, along lines 66.7 (Figs. 11a-c) and 80 (Figs. 11d-f). Likewise, the cooling effects of a La Niña are observed and modeled at the turn of the year 2010/11 along lines 80 (Figs. 11d-f) and 90 (Figs. 11g-i). The extremes match up well, as does the timing and slope of the abrupt warming 

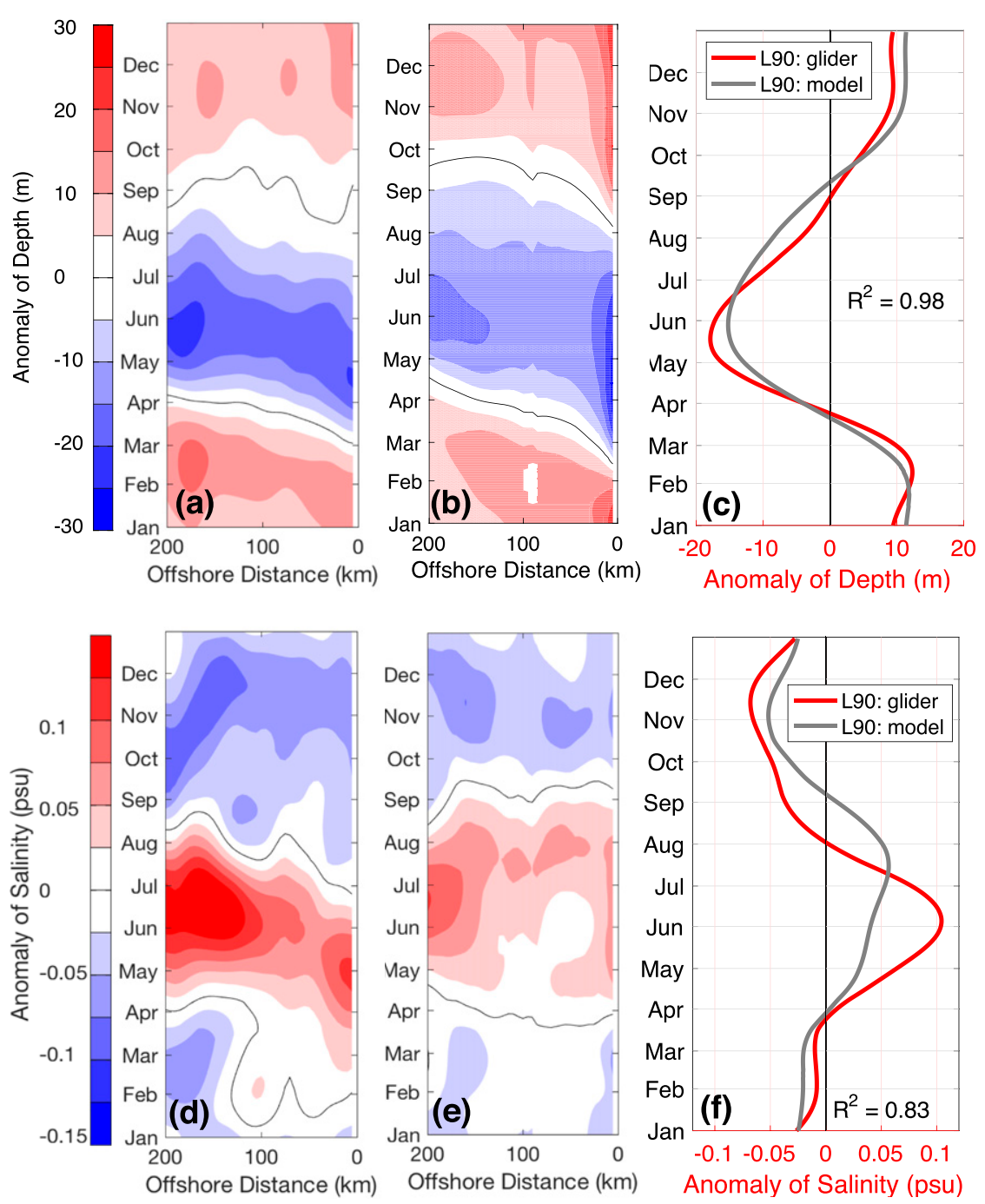

FIG. 9. Annual cycles of $25.3 \mathrm{~kg} \mathrm{~m}^{-3}$ isopycnal (a)-(c) depth anomaly (positive indicates deep) and (d)-(f) salinity anomaly along line 90 . The Hovmöller plots show the (left) glidermeasured and (center) modeled fields. The (right) line plots show the glider-measured (colored) and modeled (gray) anomalies averaged over the inshore $200 \mathrm{~km}$.

onset in early 2014. The exception occurs in late 2008, when CASE shows a strong but short-lived nearshore warming signal along lines 66.7 and 90 in the absence of such in the CUGN climatology. Potential temperature variability at $50 \mathrm{~m}$ is largely dominated by vertical displacements of the thermocline. Thus, we are implicitly evaluating whether CASE accurately represents upwelling and downwelling anomalies, whereby warming represents a downwelling anomaly and cooling represents an upwelling anomaly.

Looking beyond the 50-m isobar, we assess CASE's ability to reproduce the vertical structure of observed potential temperature anomalies. As before, the most striking feature of the depth-dependent interannual potential temperature anomaly is the persistent 2014-16 warming (Fig. 12). The CUGN climatology and CASE show comparable vertical structure, magnitude, abrupt onset, and duration of the warming, though the modeled anomalies do penetrate deeper than the observed anomalies along all three lines. As in Fig. 11, the warming signatures of the 2014-15 marine heatwave and 2015-16 El Niño are distinct along line 90 but not along lines 66.7 or 80 (Fig. 12). Along line 90, the observations reveal a surface intensified maximum at the turn of the year 2014/15 and a subsurface maximum at the turn of the year 2015/16 (Fig. 12e). There is a return to nearneutral conditions between the two maxima. CASE shows weaker maxima at the same times, with the same vertical structure as the observations and a slight lull in between (Fig. 12f). Zaba and Rudnick (2016) showed 

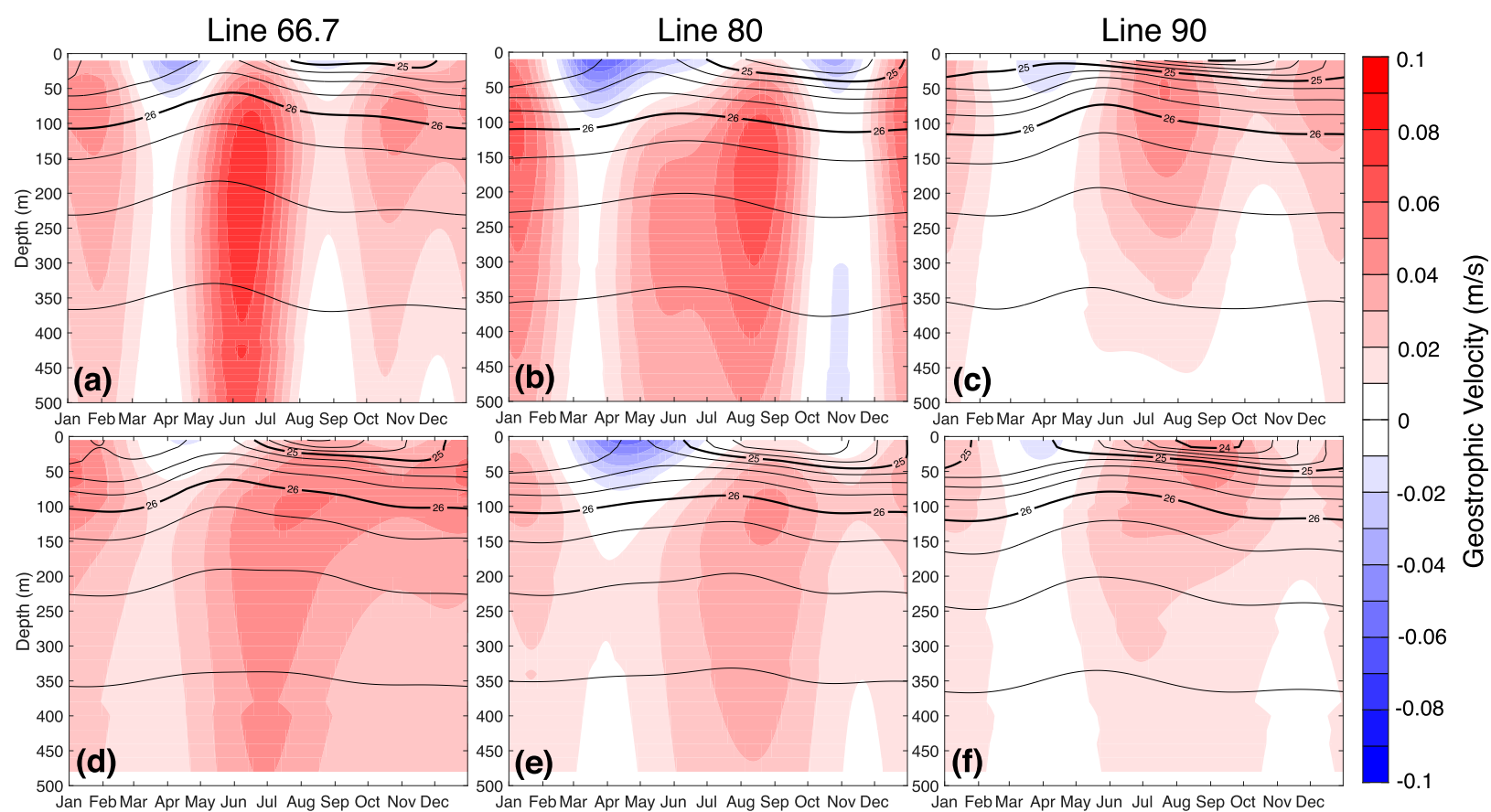

FIG. 10. Annual cycles of geostrophic velocity averaged over the inshore $150 \mathrm{~km}$ of (a),(d) line 66 and (b),(e) 80 and $200 \mathrm{~km}$ of (c),(f) line 90 and plotted as a function of time and depth for (top) glider-measured and (bottom) modeled values.

that the surface-intensified 2014-15 warming was caused by a positive heat flux anomaly into the ocean, and here the subsurface signature of the 2015-16 warming suggests that it was caused by downwelling anomalies, though the quantification of heat budgets from CASE is future work. The occurrence of anomalously upwelling favorable winds during winter 2015/16 (Frischknecht et al. 2017; Jacox et al. 2016) leaves poleward-propagating coastally trapped waves (Frischknecht et al. 2017) and anomalous horizontal advection (Chao et al. 2017b) as possible drivers of the subsurface warming. As for the warming (cooling) associated with the 2009-10 El Niño (2010-11 La Niña), CASE shows a local subsurface maximum (minimum) along lines 80 (Fig. 12d) and 90 (Fig. 12f). However, these modeled subsurface signals are hardly distinguishable amid the background variability, whereas the analogous observed signals are more pronounced (Figs. 12c,e). The model differentiates between the vertical structure of the anomalies along lines 66.7 and 80 (Figs. 12b,d; i.e., north of Point Conception, California) versus line 90 (Fig. 12f; i.e., within the SCB). Furthermore, along line 90, the model differentiates between the structure of the anomalies associated with the 2014-15 marine heatwave and the 2015-16 El Niño, suggesting that the correct mechanisms are at play in the model.

Our assessment of interannual salinity anomalies at $80-\mathrm{m}$ depth provides further evidence of realistically modeled heave in CASE. Salinity variability at that depth is largely dominated by vertical displacements of the halocline. In the CCS, freshwater lies above salty, so a negative (positive) salinity anomaly at $80 \mathrm{~m}$ represents downwelling (upwelling). The most pronounced signal along all three lines is the negative salinity anomaly during 2014-16 (Fig. 13), indicating the occurrence of a persistent downwelling anomaly. During 2014 and early 2015, the downwelling anomaly was attributed to weaker-than-normal equatorward alongshore winds (Robinson 2016; Zaba and Rudnick 2016). As with the potential temperature anomaly Hovmöller plots (Fig. 11), the modeled salinity anomaly fields (Figs. 13b,e,h) show less mesoscale structure than the observations (Figs. 13a,d,g). However, the key observed interannual features are present in the modeled field, as indicated by the strong correlation $\left(R^{2}>0.82\right)$ between the salinity fields of the two products (Figs. 13c,f,i). Salinity anomalies in the CCS exhibit an inverse relationship with equatorial temperature anomalies because an equatorial El Niño (positive temperature anomaly) causes regional downwelling in the CCS (fresh anomaly) and an equatorial La Niña (negative temperature anomaly) causes regional upwelling in the CCS (salty anomaly) via atmospheric teleconnections (Alexander et al. 2002). El Niño events are also associated with regional poleward coastally trapped waves and horizontal advection anomalies, both of which also displace isolines. 


\section{Anomaly of Potential Temperature $\left({ }^{\circ} \mathrm{C}\right)$}
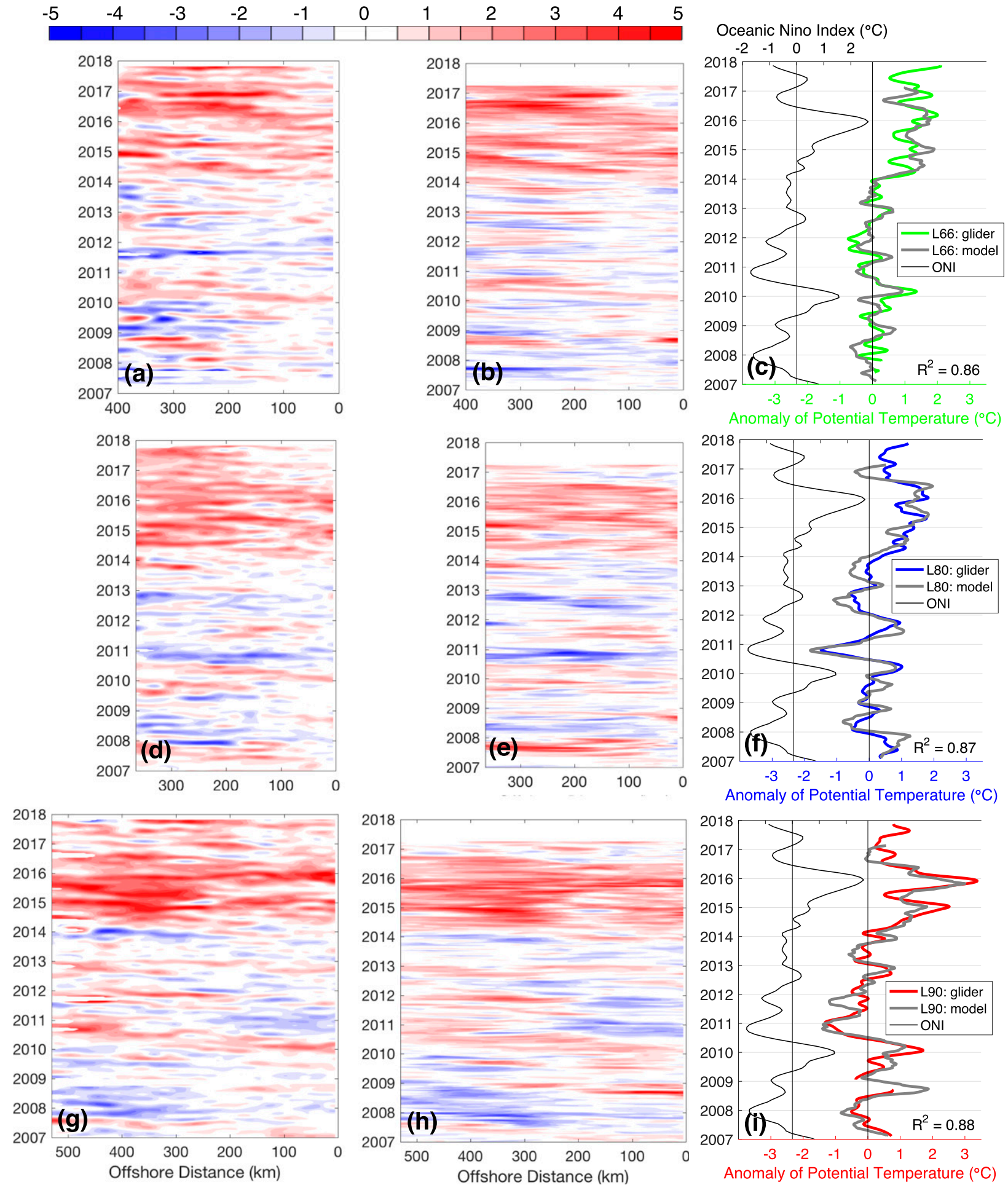

FIG. 11. Anomalies of 50-m potential temperature along lines (top) 66.7, (middle) 80, and (bottom) 90. The Hovmöller plots show (a),(d),(g) glider-measured and (b),(e),(h) modeled anomalies; the $x$ axes are different sizes because each glider line has a different offshore extent. The (c),(f),(i) line plots show the glider-measured (colored) and modeled (gray) anomalies averaged over the inshore $200 \mathrm{~km}$ of lines 66.7 (green), 80 (blue), and 90 (red). The oceanic Niño index is plotted on an offset axis in black in (c), (f), and (i). 

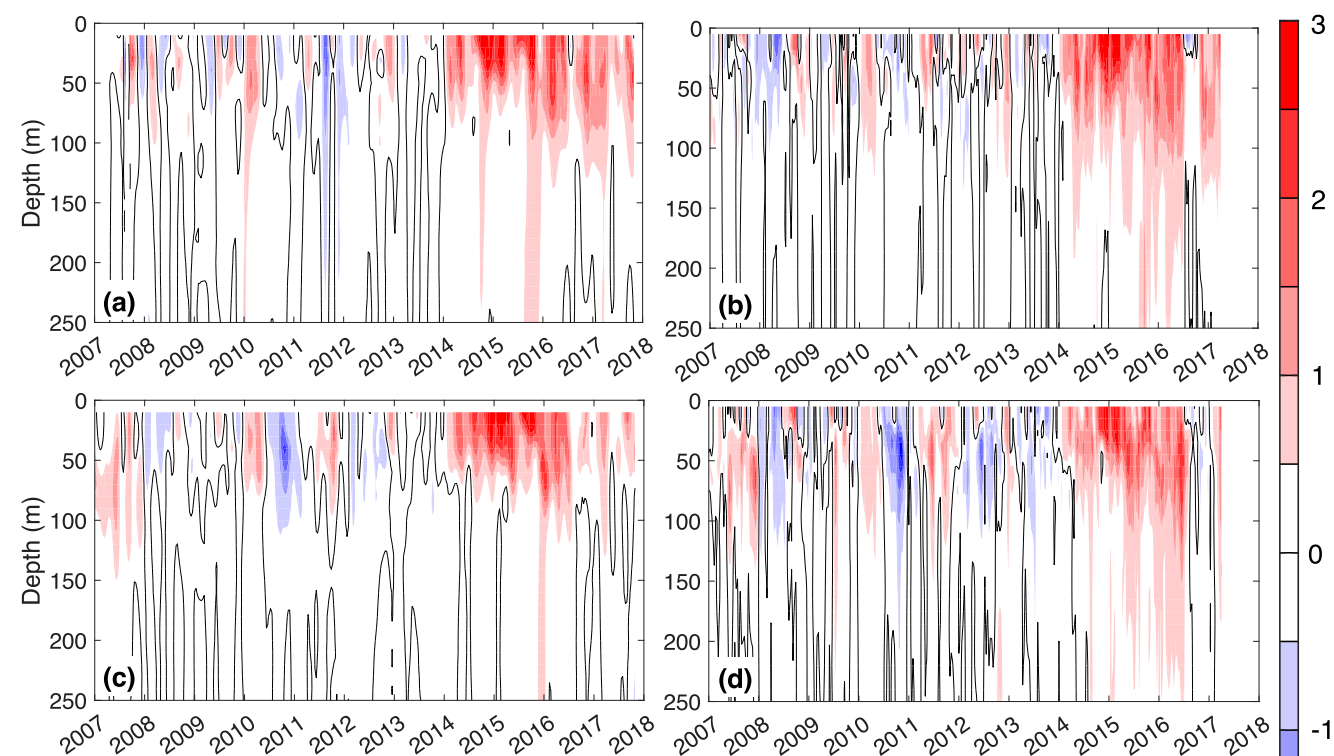

$2^{0^{01}} 2^{0^{0^{8}}} 2^{0^{09}} 2^{0^{10}} 2^{0^{1}} 2^{0^{12}} 2^{0^{13}} 2^{0^{14}} 2^{0^{15}} 2^{0^{16}} 2^{0^{11}} 2^{0^{18}}$

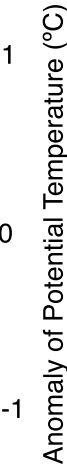
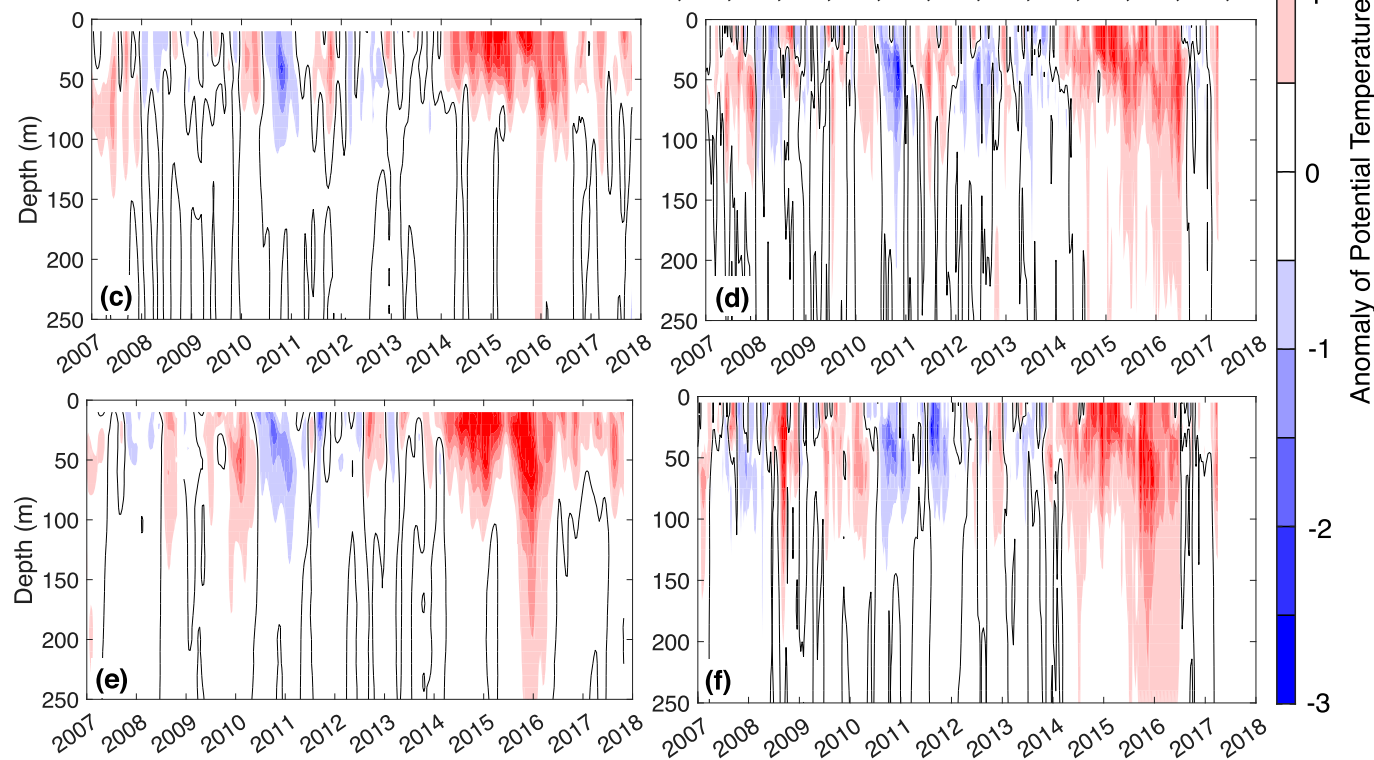

FIG. 12. Anomalies of potential temperature averaged over the inshore $200 \mathrm{~km}$ of lines (a),(b) 66.7, (c),(d) 80, and (e),(f) 90 and plotted as a function of time and depth for (left) glider-measured values and (right) model output.

When displayed as a function of depth, the observed and modeled salinity anomalies exhibit the same vertical structures (Fig. 14). The subsurface salinity anomaly minima during 2014-16 are roughly centered at 80-m depth and represent the sustained downward displacement of the halocline. There are some differences between the 2014-16 freshening signatures along the three different lines; for example, line 66.7 has three distinct pulses of freshening that extend all the way to the surface (Figs. 14a,b) and line 80 shows the weakest freshening signal (Figs. 14c,d). However, a subsurface freshening signal is present along all three lines in the observations and model. The realistic model representation of the 2014-16 subsurface salinity anomaly implies that CASE simulates the position and magnitude of the sharp salinity gradient of the halocline, as well as the magnitude of the anomalous halocline heave. Prior to 2014, the $80-\mathrm{m}$ salinity anomaly field along all lines shows relatively higher frequency variability with no prolonged or notable anomalous features (Fig. 14).

Once again isolating the effect of horizontal isopycnal processes from isopycnal heave, we focus on the
$26.0 \mathrm{~kg} \mathrm{~m}^{-3}$ isopycnal along line 90 . In terms of vertical processes, the observations and model agree with respect to the phase and magnitude of the anomalous isopycnal deepening during the 2009-10 El Niño, the anomalous shoaling during the 2010-11 La Niña, and the anomalous deepening during 2014-16 (Figs. 15a-c). One apparent discrepancy between the two products occurs between the latter two events, when there is a brief lull in the anomalous depth of the observed isopycnal but not the modeled isopycnal (Fig. 15c). In terms of horizontal isopycnal processes, the observed and modeled isopycnal salinity anomaly fields both show a pronounced positive anomaly at the turn of the year 2015/16 during peak equatorial El Niño (Figs. 15d-f). At its peak, the modeled isopycnal salinity anomaly is $22 \%$ weaker than the observed one, however, the phases and durations of the signals do match up. In the CCS domain, relatively saltier water lies to the south, so Rudnick et al. (2017) attributed the observed spike in salinity to anomalous poleward advection during the El Niño. Anomalous advection was also observed during the strong 1997-98 El Niño (Lynn and Bograd 2002). 


\section{Anomaly of Salinity (psu)}

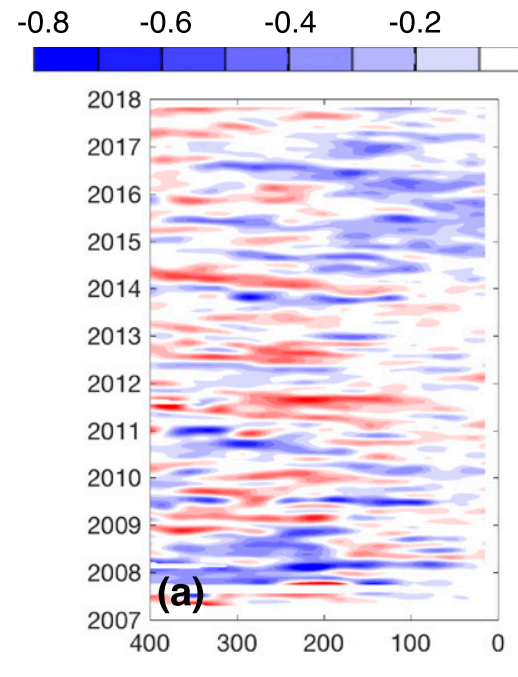

\begin{tabular}{l|l|l|l|l}
\hline & 0.2 & 0.4 & 0.6 & 0.8
\end{tabular}
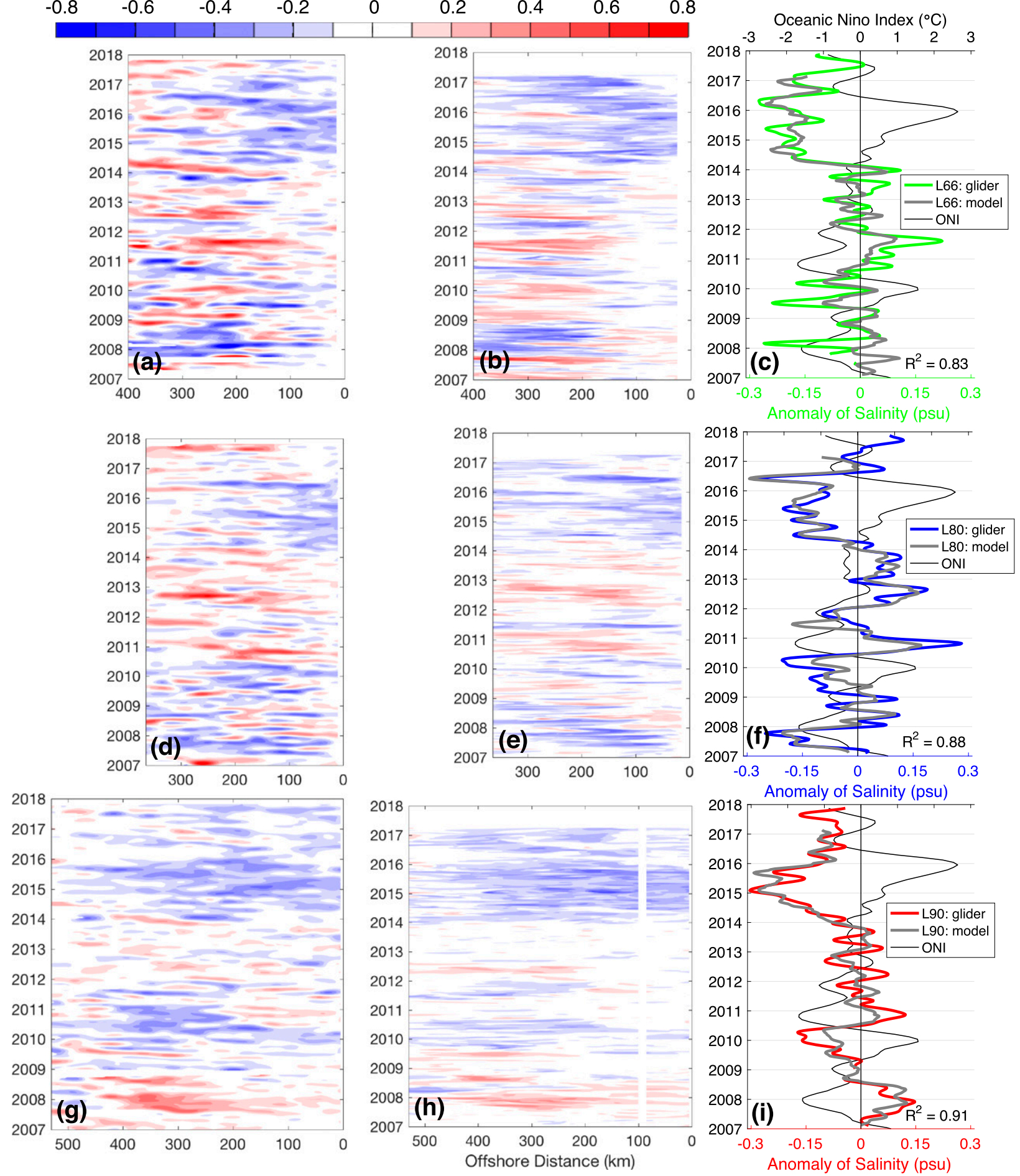

FIG. 13. As in Fig. 11, but for anomalies of 80-m salinity. 

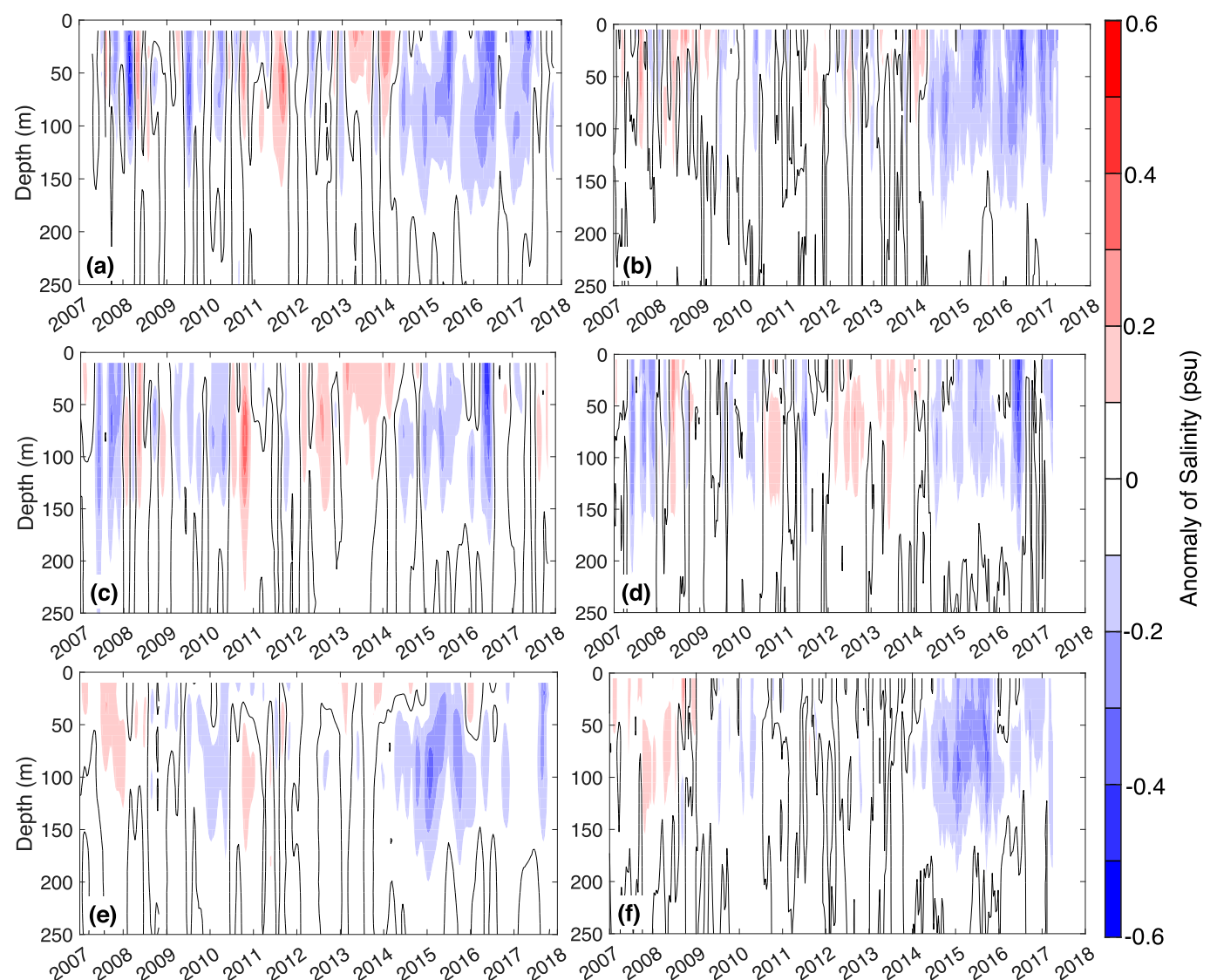

FIG. 14. As in Fig. 12, but for anomalies of salinity.

An observed feature along line 90 that is not resolved by CASE is the low-frequency shift from salty to fresh at the turn of the year 2009/10.

\section{Summary}

This paper presents over 10 years of output from the California State Estimate (http://www.ecco.ucsd.edu/ case.html). To assess the realism of the model, we compare CASE solutions with 1) withheld data and 2) assimilated data. The withheld data include temperature and salinity from CalCOFI, as well as CUGN velocity; the assimilated data include CUGN temperature and salinity measurements. Taking advantage of the structure and methods of the CUGN climatology, we processed the CASE output as the CUGN data and compared the products with respect to their mean fields, annual cycles, and interannual anomaly fields. Several important conclusions follow from the presented comparisons. First, CASE resolves the key large-scale features and gradients of the region's time-mean circulation pattern and thermohaline structure, though we note that the modeled mean potential temperature field shows better consistency with observations than the mean salinity field. Second, CASE accurately reproduces the phase and, to a lesser extent, the magnitude of several CCS annual signals, including the increase in surface temperature, salinity, and stratification from late summer through fall; the wind-driven upwelling of isolines and near-surface mixing during spring; and the semiannual cycle of the CU. Third, CASE realistically captures CCS interannual variability, most notably the persistent warming and downwelling anomalies during 2014-16, as well as the positive isopycnal salinity anomaly during the 2015-16 El Niño. Off the lines, CASE fills in the data gaps, resolving flow continuity of the CU and CC (Fig. 1a), alongshore gradients (Fig. 1), and the alongshore propagation of signals (not shown).

The comparison also revealed a few discrepancies between the products, which need to be considered in the future development and application of CASE. First, the largest biases of the potential temperature and salinity fields occur near the surface and the depths of the thermocline and halocline (Figs. 5c,d), respectively. Underestimated temperature and salinity variances (Figs. 5c,d) indicate the difficulty of accurately modeling 

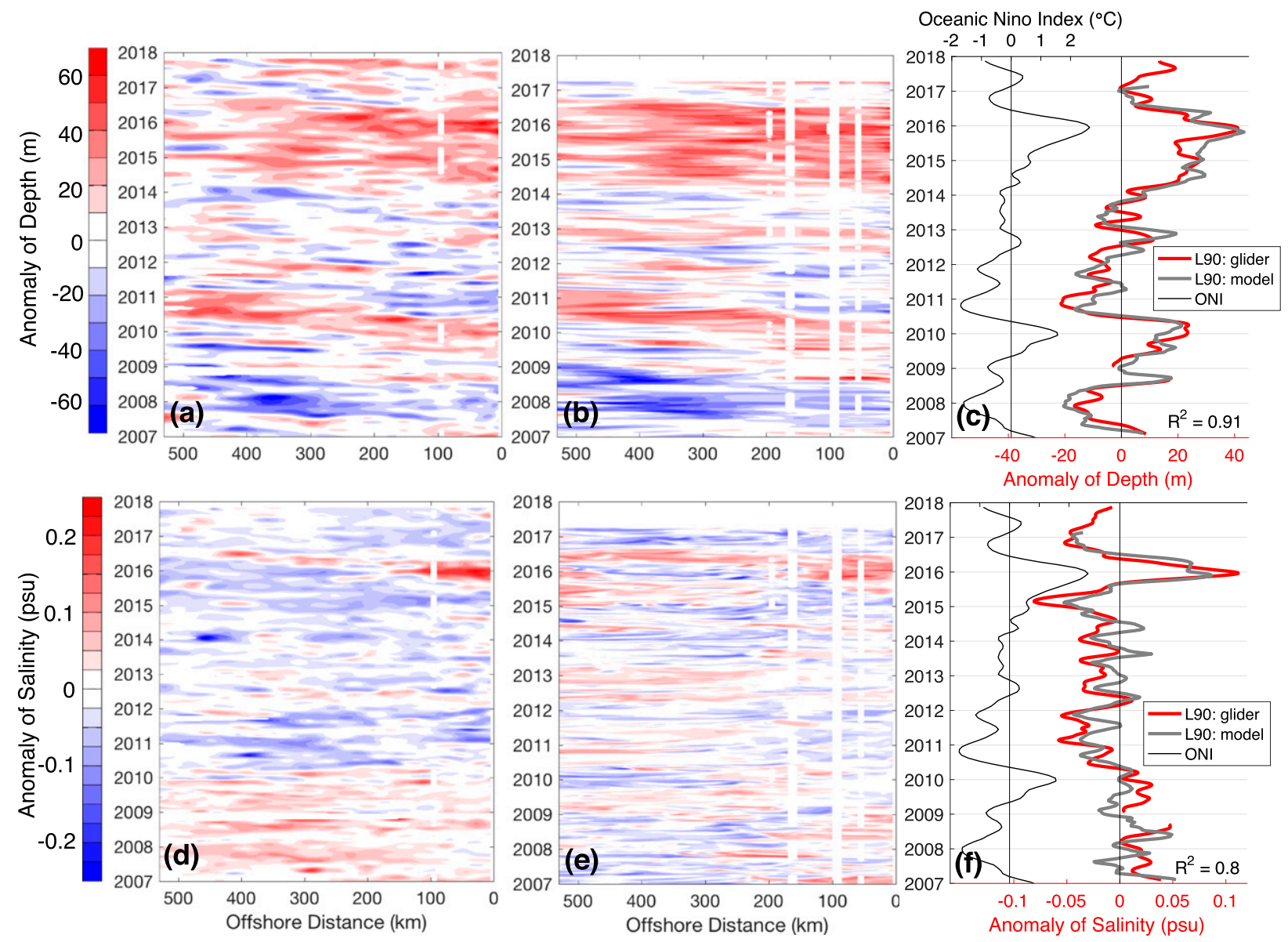

FIG. 15. Anomalies of (a)-(c) $26.0 \mathrm{~kg} \mathrm{~m}^{-3}$ isopycnal depth anomaly (positive indicates deep) and (d)-(f) $26.0 \mathrm{~kg} \mathrm{~m}^{-3}$ isopycnal salinity anomaly along line 90 . The Hovmöller plots show the (left) glider-measured and (center) modeled anomalies. The (right) line plots show the glider-measured (colored) and modeled (gray) anomalies averaged over the inshore $200 \mathrm{~km}$ of line 90 . The oceanic Niño index is plotted on an offset axis in black in (c) and (f).

depth ranges within elevated vertical gradients, where variability is high as a result of vertical displacements (i.e., error scales with the variability). The relatively large offset values near the surface (Figs. 5c,d) indicate the difficultly of modeling shallow processes, which largely rely on the accuracy of the surface forcing and turbulence parameterizations. Second, we showed that CASE's mean salinity field has a positive bias in the offshore CC region of the domain, which results in weaker across-shore salinity and potential density gradients. Third, the CASE annual cycle overestimates surface temperature and stratification in the early fall, underestimates upward isoline heave in the spring, and lags the summertime $\mathrm{CU}$ and near-surface isopycnal salinity maxima. These phase lags are likely due to the model's 2D and 3D smoothing of control variables, which acts as a noncentered filtering window that lags assimilated observations. This effect is most apparent in underdetermined variables like salinity and geostrophic velocity (which is derived from salinity), less so in variables like temperature. Fourth, CASE's interannual anomaly fields show some differences relative to the CUGN climatology: a strong but shortlived warming in late 2008 along lines 66.7 and 90 that is not present in the observations (Figs. 11a-c,g-i), 2014-16 potential temperature anomalies that penetrate deeper than those of the observations (Fig. 12), and a lack of the observed low-frequency salty to fresh shift along the $26.0 \mathrm{~kg} \mathrm{~m}^{-3}$ isopycnal along line 90 at the turn of the year 2009/10 (Figs. 15d,e). We itemize these discrepancies to emphasize the value of comparing model output with assimilated data because there is no guarantee that the two will agree everywhere given other imposed constraints. Our comparison highlights locations, in this case the offshore CC, where initial conditions, boundary conditions, and mixing parameterizations need to be further investigated for realism or, at the very least, where scientific analysis must consider the revealed biases. 


\section{Discussion}

Here we have taken the traditional approach of examining variables along sections, which has long been the cornerstone of descriptive physical oceanography. It continues to be applied to modern data products that are improving with respect to resolution and fidelity. This approach allows for the identification of physical structures, variability, and the possible governing processes. An atlas of plots from the CUGN had already been generated and discussed (Rudnick et al. 2017), and from it we derived the most relevant signals and metrics for the CCS region. In this paper, we do the same for CASE. For example, several of these metrics $\left(T_{50 \mathrm{~m}}, S_{80 \mathrm{~m}}\right.$, and $\left.z_{26 \mathrm{~kg} / \mathrm{m} 3}\right)$ are affected by upwelling and downwelling, here traditionally defined as the vertical displacement of properties. These local vertical displacements are caused by some combination of wind-driven vertical velocity, coastally trapped waves, lateral advection of gradients, and even diapycnal mixing. Identifying the exact cause at any particular location and time requires an examination of the terms in the budgets, which we plan in future work with CASE.

Model evaluation is a necessary step before using CASE to quantify mass, heat, and salt budgets, with the goal of diagnosing which mechanisms force the observed seasonal and interannual variability of the regional circulation and thermohaline structure. Given the results of our model-data comparison, we justify the use of CASE for anomaly attribution, which is only possible if the model realistically depicts CCS variability at the temporal scales of interest. We are working on quantifying the contribution of relevant physical processes (atmospheric heat flux, horizontal and vertical advection, mixing) to the observed changes in heat content during the prolonged warm period of 2014-16. CASE offers the possibility to study the similarities, differences, and spatiotemporal variability of the regional heating mechanisms of two sequential climate events.

Our model-data comparison considers several relevant physical variables and a range of depths. We aimed to conduct a comprehensive comparison of the CUGN climatology versus CASE and hope that our method can provide a framework for others who might use the CUGN climatology for model evaluation in the CCS region. Numerical reanalyses and forecasts alike have become critical components of CCS research (Chao et al. 2017b; Frischknecht et al. 2017; Jacox et al. 2016; Kurapov et al. 2017). The modeling community continues to make progress toward increasingly realistic models, but issues remain, for example, the effect of uncertainties in initial conditions, surface forcing, and open boundary conditions on modeled fields. Model development and evolution relies heavily on rigorous and methodical model evaluations, for which the CUGN climatology can be a valuable tool because it is a sustained and uniquely dense regional time series. Identifying and troubleshooting model biases allows model error quantification and can lead to attribution and repair. Furthermore, this work provides a suggested set of metrics for assessing model simulations of the CCS region. In doing so we describe the CCS physical oceanography, highlighting the most important aspects to numerically reproduce.

Acknowledgments. The California Underwater Glider Network is made possible by the Instrument Development Group at Scripps Institution of Oceanography, including Jeff Sherman, Kyle Grindley, Ben Reineman, Evan Randall-Goodwin, and Derek Vana; we thank them for their professionalism. This work was supported by the National Oceanic and Atmospheric Administration (NOAA) Ocean Observing and Monitoring Division through Grant NA15OAR4320071 and by the NOAA Integrated Ocean Observing System through Grant NA16NOS012022. Additional salary support was provided by the National Science Foundation through Grant OCE1232971. The MITgcm source code is available online (https://github.com/MITgcm/MITgcm). The SSALTO/DUACS altimeter products were produced and distributed by the Copernicus Marine and Environment Monitoring Service (CMEMS; http:// marine.copernicus.eu/). We gratefully acknowledge the ECCO consortium, including MIT, JPL, and the University of Hamburg.

\section{REFERENCES}

Alexander, M. A., I. Bladé, M. Newman, J. R. Lanzante, N. C. Lau, and J. D. Scott, 2002: The atmospheric bridge: The influence of ENSO teleconnections on air-sea interaction over the global oceans. J. Climate, 15, 2205-2231, https://doi.org/10.1175/15200442(2002)015<2205:TABTIO>2.0.CO;2.

Andersen, O. B., and P. Knudsen, 2009: DNSC08 mean sea surface and mean dynamic topography models. J. Geophys. Res., 114, C11001, https://doi.org/10.1029/2008JC005179.

Centurioni, L. R., J. C. Ohlmann, and P. P. Niiler, 2008: Permanent meanders in the California Current System. J. Phys. Oceanogr., 38, 1690-1710, https://doi.org/10.1175/2008JPO3746.1.

Chao, Y., and Coauthors, 2017a: Development, implementation, and validation of a California coastal ocean modeling, data assimilation, and forecasting system. Deep-Sea Res. II, 151, 49-63, https://doi.org/10.1016/j.dsr2.2017.04.013.

_ and Coauthors, 2017b: The origins of the anomalous warming in the California coastal ocean and San Francisco Bay during 2014-2016. J. Geophys. Res. Oceans, 122, 7537-7557, https:// doi.org/10.1002/2017JC013120.

Chassignet, E. P., and Coauthors, 2007: The HYCOM (Hybrid Coordinate Ocean Model) data assimilative system. J. Mar. Syst., 65, 60-83, https://doi.org/10.1016/j.jmarsys.2005.09.016. 
Cummings, J. A., 2005: Operational multivariate ocean data assimilation. Quart. J. Roy. Meteor. Soc., 131, 3583-3604, https:// doi.org/10.1256/qj.05.105.

Davis, R. E., M. D. Ohman, D. L. Rudnick, J. T. Sherman, and B. Hodges, 2008: Glider surveillance of physics and biology in the southern California Current System. Limnol. Oceanogr., 53, 2151-2168, https://doi.org/10.4319/lo.2008.53.5_part_2.2151.

Edwards, C. A., A. M. Moore, I. Hoteit, and B. D. Cornuelle, 2015: Regional ocean data assimilation. Annu. Rev. Mar. Sci., 7, 21-42, https://doi.org/10.1146/annurev-marine-010814015821.

Fiedler, P. C., and N. J. Mantua, 2017: How are warm and cool years in the California Current related to ENSO? J. Geophys. Res. Oceans, 122, 5936-5951, https://doi.org/10.1002/2017JC013094.

Frischknecht, M., M. Munnich, and N. Gruber, 2017: Local atmospheric forcing driving an unexpected California Current System response during the 2015-2016 El Niño. Geophys. Res. Lett., 44, 304-311, https://doi.org/10.1002/2016GL071316.

Gay, P. S., and T. K. Chereskin, 2009: Mean structure and seasonal variability of the poleward undercurrent off Southern California.J. Geophys. Res., 114, C02007, https://doi.org/ 10.1029/2008JC004886.

Giering, R., and T. Kaminski, 1998: Recipes for adjoint code construction. ACM Trans. Math. Software, 24, 437-474, https:// doi.org/10.1145/293686.293695.

Gilbert, J. C., and C. Lemaréchal, 1989: Some numerical experiments with variable-storage quasi-Newton algorithms. Math Program., 45, 407-435, https://doi.org/10.1007/BF01589113.

Gómez-Valdivia, F., A. Parés-Sierra, and A. L. Flores-Morales, 2017: Semiannual variability of the California Undercurrent along the Southern California Current System: A tropical generated phenomenon. J. Geophys. Res. Oceans, 122, 1574 1589, https://doi.org/10.1002/2016JC012350.

Heimbach, P., C. Hill, and R. Giering, 2002: Automatic generation of efficient adjoint code for a parallel Navier-Stokes solver. Proc. ICCS 2002, Amsterdam, Netherlands, National Oceanographic Partnership Program, 1019-1028, https://doi.org/ 10.1007/3-540-46080-2_107.

Jacox, M. G., E. L. Hazen, K. D. Zaba, D. L. Rudnick, C. A. Edwards, A. M. Moore, and S. J. Bograd, 2016: Impacts of the 2015-2016 El Niño on the California Current System: Early assessment and comparison to past events. Geophys. Res. Lett., 43, 7072-7080, https://doi.org/10.1002/ 2016GL069716.

Johnston, T. M. S., and D. L. Rudnick, 2015: Trapped diurnal internal tides, propagating semidiurnal internal tides, and mixing estimates in the California Current System from sustained glider observations, 2006-2012. Deep-Sea Res. II, 112, 61-78, https://doi.org/10.1016/j.dsr2.2014.03.009.

Kalnay, E., and Coauthors, 1996: The NCEP/NCAR 40-Year Reanalysis Project. Bull. Amer. Meteor. Soc., 77, 437-471, https:// doi.org/10.1175/1520-0477(1996)077<0437:TNYRP>2.0.CO;2.

Kurapov, A. L., N. A. Pelland, and D. L. Rudnick, 2017: Seasonal and interannual variability in along-slope oceanic properties off the US West Coast: Inferences from a high-resolution regional model. J. Geophys. Res. Oceans, 122, 5237-5259, https:// doi.org/10.1002/2017JC012721.

Large, W. G., and S. Pond, 1981: Open ocean momentum flux measurements in moderate to strong winds. J. Phys. Oceanogr., 11, 324-336, https://doi.org/10.1175/1520-0485(1981) $011<0324$ :OOMFMI $>2.0 . \mathrm{CO} ; 2$.

Ledimet, F. X., and O. Talagrand, 1986: Variational algorithms for analysis and assimilation of meteorological observations:
Theoretical aspects. Tellus, 38A, 97-110, https://doi.org/ 10.3402/tellusa.v38i2.11706.

Lynn, R. J., and J. J. Simpson, 1987: The California Current System: The seasonal variability of its physical characteristics. J. Geophys. Res., 92, 12 947-12 966, https://doi.org/10.1029/JC092iC12p12947. , and - 1990: The flow of the undercurrent over the continental borderland off southern California. J. Geophys. Res., 95, 12 995-13 008, https://doi.org/10.1029/JC095iC08p12995. and S. J. Bograd, 2002: Dynamic evolution of the 1997-1999 El Niño-La Niña cycle in the southern California Current System. Prog. Oceanogr., 54, 59-75, https://doi.org/10.1016/ S0079-6611(02)00043-5.

Marshall, J., C. Hill, L. Perelman, and A. Adcroft, 1997a: Hydrostatic, quasi-hydrostatic, and nonhydrostatic ocean modeling. J. Geophys. Res., 102, 5733-5752, https://doi.org/10.1029/96JC02776.

A. Adcroft, C. Hill, L. Perelman, and C. Heisey, 1997b: A finite-volume, incompressible Navier Stokes model for studies of the ocean on parallel computers. J. Geophys. Res., 102, 5753-5766, https://doi.org/10.1029/96JC02775.

Mazloff, M. R., S. T. Gille, and B. Cornuelle, 2014: Improving the geoid: Combining altimetry and mean dynamic topography in the California coastal ocean. Geophys. Res. Lett., 41, 89448952, https://doi.org/10.1002/2014GL062402.

Murphy, A. H., 1992: Climatology, persistence, and their linear combination as standards of reference in skill scores. Wea. Forecasting, 7, 692-698, https://doi.org/10.1175/1520-0434(1992) 007<0692:CPATLC $>2.0$. CO;2.

Neveu, E., A. Moore, C. Edwards, J. Fiechter, P. Drake, W. Crawford, M. Jacox, and E. Nuss, 2016: An historical analysis of the California Current circulation using ROMS 4D-Var: System configuration and diagnostics. Ocean Modell., 99, 133-151, https://doi.org/10.1016/j.ocemod.2015.11.012.

Oke, P. R., J. S. Allen, R. N. Miller, and G. D. Egbert, 2002: A modeling study of the three-dimensional continental shelf circulation off Oregon. Part II: Dynamical analysis. J. Phys. Oceanogr., 32, 1383-1403, https://doi.org/10.1175/1520-0485(2002) 032<1383:AMSOTT $>2.0$. CO;2.

Pavlis, N. K., S. A. Holmes, S. C. Kenyon, and J. K. Factor, 2012: The development and evaluation of the Earth Gravitational Model 2008 (EGM2008). J. Geophys. Res., 117, B04406, https://doi.org/10.1029/2011JB008916.

Robinson, C. J., 2016: Evolution of the 2014-2015 sea surface temperature warming in the central west coast of Baja California, Mexico, recorded by remote sensing. Geophys. Res. Lett., 43, 7066-7071, https://doi.org/10.1002/2016GL069356.

Rudnick, D. L., K. D. Zaba, R. E. Todd, and R. E. Davis, 2017: A climatology of the California Current System from a network of underwater gliders. Prog. Oceanogr., 154, 64-106, https:// doi.org/10.1016/j.pocean.2017.03.002.

Schwing, F. B., T. Murphree, L. deWitt, and P. M. Green, 2002: The evolution of oceanic and atmospheric anomalies in the northeast Pacific during the El Niño and La Niña events of 1995-2001. Prog. Oceanogr., 54, 459-491, https://doi.org/ 10.1016/S0079-6611(02)00064-2.

Sherman, J., R. E. Davis, W. B. Owens, and J. Valdes, 2001: The autonomous underwater glider "spray." IEEE J. Oceanic Eng., 26, 437-446, https://doi.org/10.1109/48.972076.

Stammer, D., and Coauthors, 2002: Global ocean circulation during 1992-1997, estimated from ocean observations and a general circulation model. J. Geophys. Res., 107, 3118, https:// doi.org/10.1029/2001JC000888.

Todd, R. E., D. L. Rudnick, and R. E. Davis, 2009: Monitoring the greater San Pedro Bay region using autonomous underwater 
gliders during fall of 2006. J. Geophys. Res., 114, C06001, https://doi.org/10.1029/2008JC005086.

$-, \ldots, \ldots$, and M. D. Ohman, 2011a: Underwater gliders reveal rapid arrival of El Niño effects off California's coast. Geophys. Res. Lett., 38, L03609, https://doi.org/10.1029/ 2010GL046376.

, — - M. R. Mazloff, R. E. Davis, and B. D. Cornuelle, 2011b: Poleward flows in the southern California Current System: Glider observations and numerical simulation. J. Geophys. Res., 116, C02026, https://doi.org/10.1029/2010JC006536.

_ — — — - B. D. Cornuelle, and R. E. Davis, 2012: Thermohaline structure in the California Current System:
Observations and modeling of spice variance. J. Geophys. Res., 117, C02008, https://doi.org/10.1029/2011JC007589.

Verdy, A., M. R. Mazloff, B. D. Cornuelle, and S. Y. Kim, 2014: Wind-driven sea level variability on the California coast: An adjoint sensitivity analysis. J. Phys. Oceanogr., 44, 297-318, https://doi.org/10.1175/JPO-D-13-018.1.

Wunsch, C., 1996: The Ocean Circulation Inverse Problem. Cambridge University Press, 442 pp.

Zaba, K. D., and D. L. Rudnick, 2016: The 2014-2015 warming anomaly in the Southern California Current System observed by underwater gliders. Geophys. Res. Lett., 43, 1241-1248, https://doi.org/10.1002/2015GL067550. 